\title{
Comparison of measured and calculated collision efficiencies at low temperatures
}

\author{
B. Nagare ${ }^{1}$, C. Marcolli ${ }^{1,2}$, O. Stetzer ${ }^{1}$, and U. Lohmann ${ }^{1}$ \\ ${ }^{1}$ Institute for Atmospheric and Climate Science, ETH, Zurich, Switzerland \\ ${ }^{2}$ Marcolli Chemistry and Physics Consulting GmbH, Zurich, Switzerland \\ Correspondence to: C. Marcolli (claudia.marcolli@env.ethz.ch)
}

Received: 19 March 2015 - Published in Atmos. Chem. Phys. Discuss.: 23 April 2015

Revised: 1 October 2015 - Accepted: 27 November 2015 - Published: 15 December 2015

\begin{abstract}
Interactions of atmospheric aerosols with clouds influence cloud properties and modify the aerosol life cycle. Aerosol particles act as cloud condensation nuclei and ice nucleating particles or become incorporated into cloud droplets by scavenging. For an accurate description of aerosol scavenging and ice nucleation in contact mode, collision efficiency between droplets and aerosol particles needs to be known. This study derives the collision rate from experimental contact freezing data obtained with the ETH CoLlision Ice Nucleation CHamber (CLINCH). Freely falling $80 \mu \mathrm{m}$ diameter water droplets are exposed to an aerosol consisting of 200 and $400 \mathrm{~nm}$ diameter silver iodide particles of concentrations from 500 to 5000 and 500 to $2000 \mathrm{~cm}^{-3}$, respectively, which act as ice nucleating particles in contact mode. The experimental data used to derive collision efficiency are in a temperature range of $238-245 \mathrm{~K}$, where each collision of silver iodide particles with droplets can be assumed to result in the freezing of the droplet. An upper and lower limit of collision efficiency is also estimated for $800 \mathrm{~nm}$ diameter kaolinite particles. The chamber is kept at ice saturation at a temperature range of 236 to $261 \mathrm{~K}$, leading to the slow evaporation of water droplets giving rise to thermophoresis and diffusiophoresis. Droplets and particles bear charges inducing electrophoresis. The experimentally derived collision efficiency values of $0.13,0.07$ and $0.047-0.11$ for 200 , 400 and $800 \mathrm{~nm}$ particles are around 1 order of magnitude higher than theoretical formulations which include Brownian diffusion, impaction, interception, thermophoretic, diffusiophoretic and electric forces. This discrepancy is most probably due to uncertainties and inaccuracies in the description of thermophoretic and diffusiophoretic processes acting together. This is, to the authors' knowledge, the first data set of
\end{abstract}

collision efficiencies acquired below $273 \mathrm{~K}$. More such experiments with different droplet and particle diameters are needed to improve our understanding of collision processes acting together.

\section{Introduction}

Interactions of atmospheric aerosols with clouds influence the cloud properties and modify the aerosol life cycle. Depending on particle size, morphology and chemical composition, aerosol particles act as cloud condensation nuclei (CCN) and ice nucleating particles (INP) or become incorporated into cloud droplets by scavenging. Scavenging of particles in the air is one of the major processes by which the atmosphere is cleansed (Radke et al., 1980). Particles may be scavenged in-cloud and below-cloud due to collision with droplets (impaction scavenging) or by nucleation scavenging when they serve as CCN or INP (Leong et al., 1982). Below $273 \mathrm{~K}$ solid aerosol particles that activate to cloud droplets may induce droplet freezing in immersion mode when the temperature is further decreased. This freezing process is usually discriminated from condensation freezing, where $\mathrm{CCN}$ activation is immediately followed by ice formation. When interstitial aerosol particles collide with supercooled cloud droplets they may induce freezing in contact mode. This nucleation process deserves special attention, since it is reported to induce ice nucleation at a higher temperature than when the same particle acts as INP in immersion or condensation mode (Durant and Shaw, 2005; Fornea et al., 2009; Ladino Moreno et al., 2013). In addition, the importance of contact nucleation for cloud glaciation also de- 
pends on the collision efficiency between aerosol and cloud droplets.

Collisions between particles and droplets can result from motion induced by turbulence and Brownian diffusion or as a result of external forces induced by gravity, electric charges, temperature or vapor gradients (Leong et al., 1982). There exist different formulations that describe collision efficiencies theoretically and give mathematical expressions for them (Slinn, 1983; Park et al., 2005; Andronache et al., 2006; Wang and Pruppacher, 1977). These schemes were developed and applied mostly for rain conditions at $T>0{ }^{\circ} \mathrm{C}$. To validate theoretical calculations, laboratory studies have been carried out in which aerosols have been exposed to falling droplets (see Wang et al., 1978, and Ladino et al., 2011a, for references). Most of these studies have been performed at or close to room temperature with droplets of sizes that are typical for drizzle and rain rather than for cloud droplets. Measurements of pre- and post-rain aerosol concentrations have been used to quantify aerosol scavenging by precipitation (Davenport and Peters, 1978; Laakso et al., 2003; Chate and Pranesha, 2004; Maria and Russell, 2005). These studies often show too large a washout compared with theoretical estimates based on formulations of collision efficiencies (Andronache et al., 2006). One reason for this might be an inaccurate representation of the collision processes. Accurate estimates of collision efficiencies are also needed to describe cloud glaciation. To date, there is a lack of atmospheric INP that might explain ice nucleation at temperatures higher than $-15^{\circ} \mathrm{C}$. While biological particles are discussed as candidates to close this gap (DeMott et al., 2010), an alternative explanation would be ice nucleation in contact mode. Several field studies have observed that ice crystals preferentially formed in regions of downdrafts and at cloud edges where dry air is entrained (Young, 1974). Particles contained in these air masses could initiate droplet freezing when they collide with them. To judge the importance of this process, nucleation and collision efficiencies have to be quantified. The representation of heterogeneous ice nucleation in most global models still lacks a detailed description of the freezing processes depending on aerosol properties and nucleation mode (Yun and Penner, 2012; Lohmann and Hoose, 2009).

Depending on particle size and the forces acting on the particles, different collision processes have to be taken into account. In models, collision efficiencies are usually calculated as the sum of the different collision processes (Andronache et al., 2006; Bae et al., 2009; Croft et al., 2010) neglecting that the forces act together to determine the aerosol path either into or around the droplet. Trajectory calculations can be used to simulate the particle pathway; however, they need to be validated with reliable laboratory measurements (Tinsley and Leddon, 2013). Calculated collision efficiencies are quite accurate for Aitken and coarse-mode particles, for which either Brownian diffusion or impaction dominates. Accumulation mode particles fall into the particle size range of the Greenfield gap (Greenfield, 1957; Seinfeld and
Pandis, 2006; Ladino et al., 2011a), where Brownian diffusion and impaction are inefficient collision mechanisms. However, the collision efficiency minimum of the Greenfield gap is reduced in the presence of electric or phoretic forces and theoretical descriptions have to include the corresponding contributions to the collision efficiencies to give accurate values. Only few experimental studies have explored this part of the parameter space (Ladino et al., 2011a; Ladino, 2011) and none of them at mixed-phase cloud temperatures.

The present study investigates collision efficiencies of 200 and $400 \mathrm{~nm}$ diameter silver iodide (AgI) particles with $80 \mu \mathrm{m}$ diameter droplets at low temperatures. A temperature range where all contacts lead to freezing is a prerequisite for the applied evaluation. This condition is fulfilled for AgI particles of 200 and $400 \mathrm{~nm}$ diameter for $T<247 \mathrm{~K}$. If AgI particles were not active in contact mode, they nevertheless should lead to nucleation in immersion mode after colliding with the droplet. In addition, we provide a lower and upper limit of collision efficiency for $800 \mathrm{~nm}$ kaolinite particles. In our experiment droplets and particles bear charges of opposite sign giving rise to electric forces. Moreover, droplets slowly evaporate in the chamber, inducing thermophoretic and diffusiophoretic forces. This study therefore provides experimental data to validate theoretical formulations exactly in this least explored parameter space range. The paper is structured as follows: Sect. 2 presents theoretical formulations of collision efficiencies from the literature; Sects. 3 and 4 describe the experimental procedure and the results. In Sect. 5, the theoretical formulations are compared with experimental results and are critically discussed. Comparison with other experimental work is presented in Sect. 6. Section 7 discusses improvements of theoretical formulations and atmospheric implications.

\section{Theory}

\subsection{Collision efficiency}

When a droplet falls through air, various processes can lead to the collision of aerosol particles with droplets. Theoretical formulations of these processes generally assume a flow around a spherical droplet capturing spherical particles. The collision efficiency $(E)$ is defined as the fraction of particles in the cylindrical volume swept out by a falling droplet that collide with the droplet. A collision efficiency of unity is realized when all the particles residing in the swept out volume of a droplet collide with the droplet. When the particles follow the airstream around the droplet, $E$ is smaller than 1 . $E$ can exceed unity when particles are scavenged by wake capture. The coalescence efficiency is defined as the fraction of particles that are retained by the droplet when they collide with them. The product of $E$ and coalescence is called the collection efficiency. Normally, it is assumed that a collision leads to the scavenging of the particle by the droplet so 
that the collision efficiency and collection efficiency are the same. Different processes have to be considered that cause deviations of the particle's movement from the airstream path and lead to the collision of aerosols with droplets (Ladino et al., 2011a). For the smallest particles, Brownian diffusion is the most important collision process. Brownian diffusion describes the random motion of aerosol particles resulting from collisions with carrier gas molecules. Brownian motion strongly depends on the particle size and is most important for small aerosol particles. Large particles are most efficiently scavenged by inertial interception and impaction. Inertial impaction occurs when a particle is unable to follow the streamlines around a falling droplet and, because of its inertia, continues to move toward the drop and is eventually captured by it (Seinfeld and Pandis, 2006). Interception takes place when a particle follows the streamlines around a falling droplet sufficiently closely to collide with it. The region of low collision efficiency between the small and large aerosol particles is known as the Greenfield gap. This gap may at least be partly closed when electric and phoretic effects contribute to particle collisions. Thermophoresis describes a net transport of particles in the presence of a temperature gradient in the air. Air molecules at a higher temperature have a higher mean velocity and therefore impart more momentum to a particle than colder ones. The momentum on the warmer side of the particle is therefore larger and moves particles from higher to lower temperatures. Since evaporation cools the droplets and induces a temperature gradient in the surrounding air, particles are attracted by droplets for relative humidity $(\mathrm{RH})<100 \%$ because of thermophoresis. Diffusiophoresis arises in the presence of a vapor concentration gradient. In the case of an evaporating droplet, there is a flux of water molecules away from the droplet, compensated for by a flux of carrier gas molecules (mainly $\mathrm{N}_{2}$, $\mathrm{O}_{2}$ ) in the opposite direction (Stefan flow) to keep the total pressure constant. Thus, thermophoresis and diffusiophoresis have opposite effects. Under typical atmospheric conditions thermophoresis dominates diffusiophoresis for aerosol particles $<1 \mu \mathrm{m}$ (Slinn and Hales, 1971). Finally, in the case of charged particles and droplets, electroscavenging has to be considered as an additional collision process. Usually, collision efficiencies of each of these processes are formulated separately and added together to yield the total collision efficiency $E_{\text {tot }}$. Park et al. (2005) and Slinn (1983) proposed formulations for the collision efficiencies by Brownian diffusion $\left(E_{\mathrm{Br}}\right)$, interception $\left(E_{\mathrm{int}}\right)$, and impaction $\left(E_{\mathrm{imp}}\right)$. Andronache et al. (2006) give formulations for thermophoresis $\left(E_{\mathrm{Th}}\right)$, diffusiophoresis $\left(E_{\mathrm{Df}}\right)$, and electrophoresis $\left(E_{\mathrm{El}}\right)$. Wang et al. (1978) use a flux model to calculate collision rate coefficients for electric and phoretic scavenging. In the following, we will outline the formulations proposed for the different collision processes.

\subsection{Brownian diffusion, interception and impaction}

In the approaches by Park et al. (2005), hereafter referred to as P05, and Slinn (1983), hereafter referred to as S83, collision efficiencies of Brownian diffusion, interception and impaction $\left(E_{\mathrm{Br}, \mathrm{I}}\right)$ are provided. They are calculated separately and added together.

$E_{\mathrm{Br}, \mathrm{I}}=E_{\mathrm{Br}}+E_{\mathrm{int}}+E_{\mathrm{imp}}$

\subsubsection{Formulation by Park (P05)}

For collision efficiencies due to Brownian diffusion and interception Park et al. (2005) follow Jung and Lee (1998), who used a resolved flow field around a system consisting of multiple spheres to obtain an analytical solution including the effects of induced internal circulation inside a liquid droplet. Due to the influence of the internal flow, the outer flow velocity around the fluid spheres becomes larger than that around solid spheres. For this reason, the streamlines pass around a fluid sphere more closely than around a solid sphere. The collision efficiency due to Brownian diffusion is taken from Park et al. (2005):

$E_{\mathrm{Br}}\left(d_{\mathrm{p}}, D_{\mathrm{d}}\right)=2\left(\frac{\sqrt{3} \pi}{4 P e}\right)^{\frac{2}{3}}\left(\frac{(1-\alpha)(3 \sigma+4)}{(J+\sigma K)}\right)^{\frac{1}{3}}$,

where $\alpha$ is the packing density, i.e., the water volume present in a unit volume of air and $\sigma$ the viscosity ratio of water to air. The hydrodynamic factors $J$ and $K$ are given as

$$
\begin{aligned}
& J=1-\frac{6}{5} \alpha^{\frac{1}{3}}+\frac{1}{5} \alpha^{2}, \\
& K=1-\frac{9}{5} \alpha^{\frac{1}{3}}+\alpha+\frac{1}{5} \alpha^{2},
\end{aligned}
$$

and $P e$ is the Péclet number defined as the ratio between the advective and diffusive transport rate and is given as

$P e=\frac{D_{\mathrm{d}} U\left(D_{\mathrm{d}}\right)}{D_{\mathrm{diff}}}$,

where $D_{\mathrm{d}}$ is the droplet diameter, $U\left(D_{\mathrm{d}}\right)$ is the terminal velocity of the drop and $D_{\text {diff }}$ the diffusion coefficient of aerosol particles given by

$D_{\text {diff }}=\frac{k_{\mathrm{B}} T_{\mathrm{a}} C_{\mathrm{c}}\left(d_{\mathrm{p}}\right)}{3 \pi \mu_{\mathrm{a}} d_{\mathrm{p}}}$,

where $k_{\mathrm{B}}$ is the Boltzmann constant, $T_{\mathrm{a}}$ is the air temperature in $\mathrm{K}, \mu_{\mathrm{a}}$ is the dynamic viscosity of air and $C_{\mathrm{c}}\left(d_{\mathrm{p}}\right)$ is the Cunningham slip correction factor to account for non-continuum effects associated with small particles. It is given as (Ladino et al., 2011a)

$C_{\mathrm{c}}\left(d_{\mathrm{p}}\right)=1+\frac{2 \lambda_{\mathrm{a}}}{d_{\mathrm{p}}}\left[1.257+0.4 \exp \frac{-1.1 d_{\mathrm{p}}}{2 \lambda_{\mathrm{a}}}\right]$, 
where $\lambda_{\mathrm{a}}$ is the mean free path of air molecules. The temperature-dependent viscosity of air $\left(\mu_{\mathrm{a}}\right)$ is taken from the parameterization in Pruppacher and Klett (1997). In poise units, it is given as

$\mu_{\mathrm{a}}=\frac{1.718+0.0049 T_{\mathrm{c}}-0.000012 T_{\mathrm{c}}^{2}}{10^{-4}}$,

where $T_{\mathrm{c}}$ is the temperature in ${ }^{\circ} \mathrm{C}$. For the viscosity of water, the lowest measured value at $273 \mathrm{~K}$ is used $\left(1.787 \times 10^{-3} \mathrm{~kg} \mathrm{~m}^{-1} \mathrm{~s}^{-1}\right)$.

According to Jung and Lee (1998), the collision efficiency due to interception $E_{\text {int }}$ is given as

$$
\begin{aligned}
& E_{\text {int }}\left(d_{\mathrm{p}}, D_{\mathrm{d}}\right)= \\
& \quad \frac{1-\alpha}{J+\sigma K}\left[\frac{R}{1+R}+\frac{1}{2}\left(\frac{R}{1+R}\right)^{2}(3 \sigma+4)\right],
\end{aligned}
$$

where $R$ is the diameter ratio between particle and droplet $\left(\frac{d_{\mathrm{p}}}{D_{\mathrm{d}}}\right)$.

The collision efficiency due to impaction ( $\left.E_{\mathrm{imp}}\right)$ is given as

$E_{\text {imp }}\left(d_{\mathrm{p}}, D_{\mathrm{d}}\right)=\left(\frac{S t k}{S t k+0.35}\right)^{2}$,

where $S t k$ is the Stokes number,

$S t k=\frac{\rho_{\mathrm{p}} d_{\mathrm{p}}^{2} U\left(D_{\mathrm{d}}\right)}{18 \mu_{\mathrm{a}} D_{\mathrm{d}}}$,

and $\rho_{\mathrm{p}}$ is the density of the particles.

\subsubsection{Formulation by Slinn (S83)}

Slinn (1983) proposed formulations for $E_{\mathrm{Br}}, E_{\text {int }}$ and $E_{\mathrm{imp}}$ using dimensional analysis coupled with experimental data which are summarized in Seinfeld and Pandis (2006). Based on Slinn (1983), the following formulations are given in Seinfeld and Pandis (2006) and Wang et al. (2010):

$$
\begin{aligned}
& E_{\mathrm{Br}}\left(d_{\mathrm{p}}, D_{\mathrm{d}}\right)=\frac{4}{\operatorname{ReSc}}\left(1+0.4 R e^{\frac{1}{2}} S c^{\frac{1}{3}}+0.16 R e^{\frac{1}{2}} S c^{\frac{1}{2}}\right), \\
& E_{\mathrm{int}}\left(d_{\mathrm{p}}, D_{\mathrm{d}}\right)=4 \frac{d_{\mathrm{p}}}{D_{\mathrm{d}}}\left[\frac{\mu_{\mathrm{a}}}{\mu_{w}}+\left(1+2 R e^{\frac{1}{2}}\right) \frac{d_{\mathrm{p}}}{D_{\mathrm{d}}}\right], \\
& E_{\mathrm{imp}}\left(d_{\mathrm{p}}, D_{\mathrm{d}}\right)=\left(\frac{\rho_{\mathrm{w}}}{\rho_{\mathrm{p}}}\right)^{\frac{1}{2}}\left(\frac{S t-S t^{*}}{S t-S t^{*}+\frac{2}{3}}\right)^{\frac{3}{2}}
\end{aligned}
$$

where $\rho_{\mathrm{w}}$ and $\rho_{\mathrm{p}}$ are densities of liquid water and particles, respectively. The normalizing factor $\frac{\rho_{\mathrm{w}}}{\rho_{\mathrm{p}}}$ is necessary to account for aerosol particles with a density $>1000 \mathrm{~kg} \mathrm{~m}^{-3}$. Re is the Reynolds number representing the ratio of inertial to viscous forces in the flow, and it is given by Pruppacher and Klett (1997):

$R e=\exp (Y)$,

where $Y$ is

$$
\begin{aligned}
Y & =-3.18657+0.992696 X-0.00153193 X^{2} \\
& -0.000987059 X^{3}-0.000578878 X^{4}+0.000085517 X^{5} \\
& -0.00000327815 X^{6},
\end{aligned}
$$

where $X=\ln \left(C d R e^{2}\right)$ and $C d R e^{2}$ is given as

$C d e^{2}=\frac{4 D_{\mathrm{d}}^{3}\left(\rho_{\mathrm{w}}-\rho_{\mathrm{a}}\right) g}{3 \mu_{\mathrm{a}}^{2}}$,

where $\rho_{\mathrm{a}}$ is the density of air and $g$ is the acceleration due to gravity. $S c$ is the Schmidt number of aerosol particles, $S t$ is the particle Stokes number given as

$S t=\frac{2 \tau\left(U\left(D_{\mathrm{d}}\right)-u\left(d_{\mathrm{p}}\right)\right)}{D_{\mathrm{d}}}$.

$U\left(D_{\mathrm{d}}\right)$ and $u\left(d_{\mathrm{p}}\right)$ are the terminal velocities of the droplets and aerosol particles, respectively. The relaxation time $\tau$ is given as (Wang et al., 2010)

$\tau=\frac{\left(\rho_{\mathrm{p}}-\rho_{\mathrm{a}}\right) d_{\mathrm{p}}^{2} C_{\mathrm{c}}}{18 \mu_{\mathrm{a}}}$.

$S t^{*}$ is the critical Stokes number above which particles may be deposited on the droplet. Note that S83 uses a slightly different formula for the Stokes number (St) than P05 (Stk). In the formulation for $E_{\text {imp }}$ given in Eq. (7), collision can happen only when $S t>S t^{*}$. The critical Stokes number is given as

$S t^{*}=\frac{1.2+\frac{1}{12} \ln (1+R e)}{1+\ln (1+R e)}$.

\subsection{Phoretic forces}

Since the droplets evaporate inside the collision chamber, thermo- and diffusiophoretic forces also contribute to the collision efficiency. Electroscavenging has to be taken into account because particles and droplets are charged. We consider the formulations of Andronache (2004) and Andronache et al. (2006), hereafter referred to as A06, where collision efficiencies are calculated separately and added together to obtain the total collision efficiency due to phoretic forces $\left(E_{\mathrm{ph}}\right)$ :

$E_{\mathrm{ph}}=E_{\mathrm{Th}}+E_{\mathrm{Df}}+E_{\mathrm{El}}$,

where $E_{\mathrm{Th}}, E_{\mathrm{Df}}$ and $E_{\mathrm{El}}$ are the collision efficiencies due to thermophoresis, diffusiophoresis and electrophoresis, respectively. 


\subsubsection{Formulation by Andronache (A06)}

The contribution of thermophoresis to the collision efficiency is given as (Andronache et al., 2006)

$E_{\mathrm{Th}}\left(d_{\mathrm{p}}, D_{\mathrm{d}}\right)=\frac{4 \gamma\left(2+0.6 \operatorname{Re}^{\frac{1}{2}} \operatorname{Pr}^{\frac{1}{3}}\right)\left(T_{\mathrm{a}}-T_{\mathrm{s}}\right)}{U\left(D_{\mathrm{d}}\right) D_{\mathrm{d}}}$,

where $T_{\mathrm{a}}$ is the absolute temperature of air, $T_{\mathrm{S}}$ is the absolute temperature at the droplet surface and $P r$ the Prandtl number for air given as

$\operatorname{Pr}=\frac{C_{p} \mu_{\mathrm{a}}}{k_{\mathrm{a}}}$.

$\gamma$ is given as

$\gamma=\frac{2 C_{\mathrm{c}}\left(k_{\mathrm{a}}+5 \frac{\lambda_{\mathrm{a}}}{D_{p}} k_{\mathrm{p}}\right) k_{\mathrm{a}}}{5 p\left(1+6 \frac{\lambda_{\mathrm{a}}}{D_{\mathrm{d}}}\right)\left(2 k_{\mathrm{a}}+k_{\mathrm{p}}+10 \frac{\lambda_{\mathrm{a}}}{D_{\mathrm{d}}} k_{\mathrm{p}}\right)}$,

where $k_{\mathrm{a}}$ and $k_{\mathrm{p}}$ are the thermal conductivities of the air and the aerosol particles, $p$ is the atmospheric pressure and $C_{p}$ is the specific heat of air at constant pressure. The diffusiophoretic contribution to collision efficiency is given as

$E_{\mathrm{Df}}\left(d_{\mathrm{p}}, D_{\mathrm{d}}\right)=\frac{4 \beta\left(2+0.6 R e^{\frac{1}{2}} S c_{\mathrm{w}}^{\frac{1}{3}}\right)\left(\frac{p_{\mathrm{s}}^{0}}{T_{\mathrm{s}}}-\frac{p_{\mathrm{a}}^{0} \mathrm{RH}}{T_{\mathrm{a}}}\right)}{U\left(D_{\mathrm{d}}\right) D_{\mathrm{d}}}$,

where

$\beta=\frac{T_{\mathrm{a}} D_{\mathrm{w}}}{p} \cdot\left(\frac{M_{\mathrm{w}}}{M_{\mathrm{a}}}\right)^{\frac{1}{2}}$.

The Schmidt number for water vapor in air is given as

$S c_{\mathrm{w}}=\frac{\mu_{\mathrm{a}}}{\rho_{\mathrm{a}} D_{\mathrm{w}}}$,

where $D_{\mathrm{w}}$ is the diffusivity of water vapor in air. For evaporating droplets, the diffusiophoretic contribution to $E$ is negative. In the formulation by Andronache et al. (2006), the contribution of electric charge to the scavenging efficiency is based on Coulomb interactions between aerosol particles and droplets carrying point charges of opposite sign, leading to the capture of particles present on the streamline close to the droplet surface. The expression for this electrostatic collision efficiency is given as (Andronache, 2004; Davenport and Peters, 1978)

$E_{\mathrm{El}}\left(d_{\mathrm{p}}, D_{\mathrm{d}}\right)=\frac{16 K C_{\mathrm{c}} Q q}{3 \pi \mu_{\mathrm{a}} D_{\mathrm{d}}^{2} d_{\mathrm{p}} U\left(D_{\mathrm{d}}\right)}$,

where $K=9 \times 10^{9} \mathrm{~N} \mathrm{~m}^{2} \mathrm{C}^{-2}$, and $Q$ and $q$ are the mean charges on the droplet and the aerosol particle in Coulomb units.

\subsubsection{The flux model (W78)}

An alternative formulation for phoretic and electrostatic forces is given by the flux model (Wang et al., 1978), hereafter referred to as W78. It expresses the thermophoretic force $F_{\mathrm{Th}}$ as (Tinsley et al., 2006)

$F_{\mathrm{Th}}=-\frac{6 \pi \mu_{\mathrm{a}} d_{\mathrm{p}}\left(k_{\mathrm{a}}+2.5 k_{\mathrm{p}} K n\right) k_{\mathrm{a}}}{5(1+3 K n)\left(k_{\mathrm{p}}+2 k_{\mathrm{a}}+5 k_{\mathrm{p}} K n\right) p} \frac{2\left(T_{\mathrm{a}}-T_{\mathrm{s}}\right)}{D_{\mathrm{d}} r^{2}}$,

where $r$ is the distance between the center of the droplet and the particle and $K n$ is the Knudsen number. The term $\frac{2\left(T_{\mathrm{a}}-T_{\mathrm{s}}\right)}{D_{\mathrm{d}} r^{2}}$ is the temperature gradient between the absolute temperature of the surrounding air $\left(T_{\mathrm{a}}\right)$ and at the droplet surface $\left(T_{\mathrm{S}}\right)$, assuming spherical symmetry. The diffusiophoretic force can be expressed as (Tinsley et al., 2006)

$F_{\mathrm{Df}}=-\frac{3 \pi \mu_{\mathrm{a}} d_{\mathrm{p}}(0.74) D_{\mathrm{w}} M_{\mathrm{a}}}{(1+\alpha K n) M_{\mathrm{w}} \rho_{\mathrm{a}}} \frac{2\left(\rho_{\nu, \mathrm{a}}-\rho_{\nu, \mathrm{s}}\right)}{D_{\mathrm{d}} r^{2}}$.

The last term in this expression, $\frac{2\left(\rho_{\nu, \mathrm{a}}-\rho_{\nu, \mathrm{s}}\right)}{D_{\mathrm{d}} r^{2}}$, is the gradient in water vapor density. $M_{\mathrm{a}}$ and $M_{\mathrm{w}}$ are the molecular weights of air and water, and $\rho_{\nu, \mathrm{a}}$ and $\rho_{\nu, \mathrm{s}}$ are the water vapor densities in the air far from the droplet and at the droplet surface, respectively. The parameter $\alpha$ is given as (Wang et al., 1978)

$\alpha=1.26+0.40 \exp \left(-1.10 K n^{-1}\right)$.

The formulation of the forces is strictly valid only for spherically symmetric inverse square fields. This is the case for stationary droplets. If the droplet moves, the temperature and vapor fields are not spherically symmetric. As a first-order correction, mean heat and vapor ventilation coefficients, $f_{\mathrm{h}}$ and $f_{\mathrm{v}}$, respectively, can be introduced to account for the effect of air motion on the flux of heat and water vapor (Tinsley, 2010). With this correction, the forces may be expressed as $F_{\mathrm{Th}}=\frac{C_{\mathrm{Th}}}{r^{2} f_{\mathrm{h}}}$ and $F_{\mathrm{Df}}=\frac{C_{\mathrm{Df}}}{r^{2} f_{\mathrm{v}}}$, where $C_{\mathrm{Th}}$ and $C_{\mathrm{Df}}$ are inverse square force constants for thermophoresis and diffusiophoresis $\left(C_{\mathrm{Th}}=f_{\mathrm{h}} F_{\mathrm{Th}} r^{2}\right.$ and $\left.C_{\mathrm{Df}}=f_{\mathrm{v}} F_{\mathrm{Df}} r^{2}\right)$. The inverse square force constants $C$ for the thermophoretic force and the diffusiophoretic force can be formulated as (Wang et al., 1978)

$$
\begin{aligned}
C_{\mathrm{Th}} & =-\frac{3 \pi \mu_{\mathrm{a}} d_{\mathrm{p}}\left(k_{\mathrm{a}}+2.5 k_{\mathrm{p}} K n\right) k_{\mathrm{a}} D_{\mathrm{d}}\left(T_{\mathrm{a}}-T_{\mathrm{s}}\right) f_{\mathrm{h}}}{5(1+3 K n)\left(k_{\mathrm{p}}+2 k_{\mathrm{a}}+5 k_{\mathrm{p}} K n\right) p}, \\
C_{\mathrm{Df}} & =-\frac{3}{2} \frac{\pi \mu_{\mathrm{a}} D_{\mathrm{d}}(0.74) D_{\mathrm{w}} M_{\mathrm{a}} d_{\mathrm{p}}\left(\rho_{\nu, \mathrm{a}}-\rho_{\nu, \mathrm{s}}\right) f_{\mathrm{v}}}{(1+\alpha K n) M_{\mathrm{w}} \rho_{\mathrm{a}}} .
\end{aligned}
$$

If electric forces are approximated by inverse square forces (repulsive for like charges, attractive for unlike charges and neglecting image charges), the inverse square force constant for electrical forces is (Tinsley, 2010)

$$
C_{\mathrm{El}}=\frac{Q q}{4 \pi \epsilon_{0}} .
$$


Using the relationship between collision efficiency and collision kernel, an effective collision efficiency can be derived from the forces. The collision kernel $K$ for each force constant $C$ can be calculated as (Ladino et al., 2011a)

$$
K=\frac{4 \pi B_{\mathrm{p}} C}{\exp \left(\frac{2 B_{\mathrm{p}} C}{D_{\mathrm{diff}} f_{\mathrm{p}} d_{\mathrm{p}}}\right)-1},
$$

where $B_{\mathrm{p}}$ is the mobility of particles. From the collision kernel, the different collision efficiencies for each mechanism can be calculated using the relationship

$$
E=\frac{4 K}{\pi\left(D_{\mathrm{d}}+d_{\mathrm{p}}\right)^{2}\left(U\left(D_{\mathrm{d}}\right)-u\left(d_{\mathrm{p}}\right)\right)} .
$$

\section{Experimental setup}

\subsection{Instrumentation}

Our CoLlision Ice Nucleation CHamber (CLINCH) is similar to the one used by Ladino et al. (2011a, b) for contact freezing studies with some modifications to observe the frozen fraction of droplets at different times. It is a continuous flow diffusion chamber which consists of two parallel plates separated by $1 \mathrm{~cm}$ with side windows for the detector. Both chamber walls are held at the same temperature and are covered with ice, leading to an environment that is saturated with respect to ice and subsaturated with respect to water. Relative humidity in the chamber depends on the chamber temperature. A droplet generator from Bremen University is placed at the center top of the chamber. The droplet generator contains a piezo element which can produce $80 \pm 3 \mu \mathrm{m}$ diameter droplets with a frequency of 100 droplets per second (Ulmke et al., 2001). With this setting the distance between two successive droplets is about $2 \mathrm{~mm}$ when the droplet acquires its terminal velocity of $0.186 \mathrm{~m} \mathrm{~s}^{-1}$. The droplets are generated with pure water (Milli-Q, $18.2 \mathrm{M} \Omega$ ) at a temperature of $281 \mathrm{~K}$. The relaxation time for a droplet to reach its terminal velocity is $0.2 \mathrm{~s}$, and the temperature relaxation time is about $0.6 \mathrm{~s}$ when the chamber is kept at $235 \mathrm{~K}$. Figure 1 shows the droplet surface temperature (panel a), the difference between droplet surface and chamber temperature (panel b) and the evolution of droplet diameter (panel c) at 255,245 and $235 \mathrm{~K}$. Aerosol particles enter the chamber at the top in an airflow from both sides and can interact with the liquid droplets while passing through the chamber. The flow through the chamber is laminar and should not show any turbulence. The terminal velocity of the AgI aerosol is too low to contribute to the flow velocity. The fall velocity of the aerosol particles is therefore taken as the flow velocity averaged over the whole cross section of the chamber, which equals $0.017 \mathrm{~m} \mathrm{~s}^{-1}$ for an airflow of $1 \mathrm{~L} \mathrm{~min}^{-1}$ through the chamber. In CLINCH, aerosol particles and cloud droplets can collide, leading to freezing of the cloud droplets via contact freezing. With the modified setup, it is possible to observe the frozen fraction of droplets at lengths of 40 and $80 \mathrm{~cm}$. The residence times of droplets at these two lengths are 2 and $4 \mathrm{~s}$, respectively. Since the droplets have to cool down to the chamber temperature after injection, the residence time at the desired temperature is shorter (see Fig. 1). In the case of the lowest investigated temperature of $235 \mathrm{~K}$, it is reduced to 1.4 and $3.4 \mathrm{~s}$ for chamber lengths of 40 and $80 \mathrm{~cm}$. At the end of the chamber, a condensation particle counter (CPC, TSI 3772) is connected to measure the concentration of the aerosol particles. In order to discriminate between water droplets and ice crystals, an Ice Optical Detector (IODE) developed inhouse (Nicolet et al., 2010) was used. In order to avoid the simultaneous presence of two droplets in the laser beam, a new laser was installed $(402 \mathrm{~nm}$, Schaefter + Kirchhoff laser Makroliniengenerator13LTM), providing a rectangular instead of a circular laser beam. The fall velocity of the droplets is $0.210 \mathrm{~m} \mathrm{~s}^{-1}$, calculated as the sum of the terminal velocity of the droplets $\left(0.186 \mathrm{~m} \mathrm{~s}^{-1}\right)$ and the flow velocity at the center of the chamber $\left(0.024 \mathrm{~m} \mathrm{~s}^{-1}\right)$ using the formula by Rogers (1988) and neglecting the temperature gradient term. The Reynolds number of the airflow is calculated to be 12 and the droplets' Reynolds numbers are about 0.65 , which ensures that the chamber flow is not turbulent. With such conditions inside the chamber, the relative humidity around the column of droplets will increase only slightly due to the evaporation of droplets. Our calculations show that this increase is $<1 \%$ and is too small to trigger deposition nucleation on the aerosol particles. Stetzer et al. (2008) showed that deposition nucleation on silver iodide particles can take place only when the relative humidity with respect to ice is larger than $105 \%$.

\subsection{Aerosol preparation}

Silver iodide particles were produced by mixing $0.1 \mathrm{M}$ potassium iodide and $0.1 \mathrm{M}$ silver nitrate solutions: $10 \mathrm{~mL}$ of the potassium iodide solution was diluted with $80 \mathrm{~mL}$ distilled water, and $10 \mathrm{~mL}$ of the silver nitrate solution were added. The volume of the AgI precipitate was then reduced to $40 \mathrm{~mL}$ by decantation, and $60 \mathrm{~mL}$ distilled water was added to the solution. From this solution aerosol particles were produced by atomizing. The particles were then dried to $\mathrm{RH}<10 \%$ at room temperature. These dried particles passed through a mixing volume to obtain a relatively constant concentration of particles. At the exit of the mixing volume, a cyclone with $1 \mu \mathrm{m}$ cutoff size was used and the particles were then passed to the differential mobility analyzer (DMA). The DMA column voltage was set to negative so that only negatively charged particles entered the airstream. The size distribution of AgI particles is lognormal with a mode diameter of $80 \mathrm{~nm}$. Size-selected 200 and $400 \mathrm{~nm}$ silver iodide particles are in the downslope of the size distribution of particles which were produced. Thus, the contribution of double or triple charged particles in the outflow of the DMA 


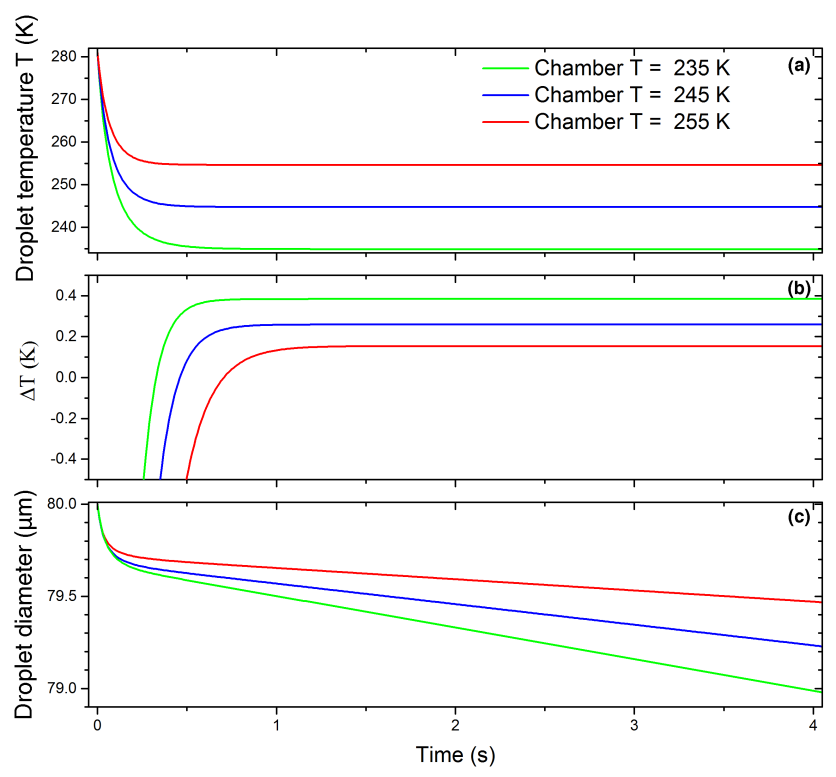

Figure 1. Droplet characteristics at experimental conditions calculated along the pathway through the chamber with time steps of $0.01 \mathrm{~s}$. Panel (a) shows the surface temperature of the droplet, (b) shows the difference between the surface temperature of the droplet and the chamber temperature and (c) shows the droplet diameter at chamber temperatures of 235, 245 and $255 \mathrm{~K}$. These parameters are calculated using Eqs. (13)-(15b) of Pruppacher and Klett (1997).

was $<10 \%$. These size-selected particles were passed to the chamber via a concentration control system in order to select a particular concentration of particles. The aerosol concentration was measured at the end of the chamber with a CPC.

\subsection{Charge measurement}

The droplets obtain a variable number of charges when the stream of droplets is injected from the droplet generator and the charge can be measured with various methods. We determined the charge off-line of the experiment by passing the droplet stream through a capacitor consisting of two parallel plates which were connected to a DC voltage supply. The droplet generator was placed exactly at the top edge of the plates. These two plates were kept at $6 \mathrm{~mm}$ distance from each other and a DC voltage was applied. Due to the presence of the charge on the droplets, the droplets can be either deflected toward the positively or negatively charged plate. Multiple measurements were performed at different times in order to obtain the average charge on the particles. Figure 2 shows the individual measurements of the charge on the droplets. The charge on the droplets varied from $0.16 \mathrm{fC}$ (1000 e) to $80 \mathrm{fC}(50000 \mathrm{e})$. It remained the same once the droplet generator was turned on but could switch to a different value when the droplet stream was turned off and turned on again. The mean charge on the droplets was about $65 \mathrm{fC}$ $(39000 \mathrm{e} \pm 20000 \mathrm{e})$.

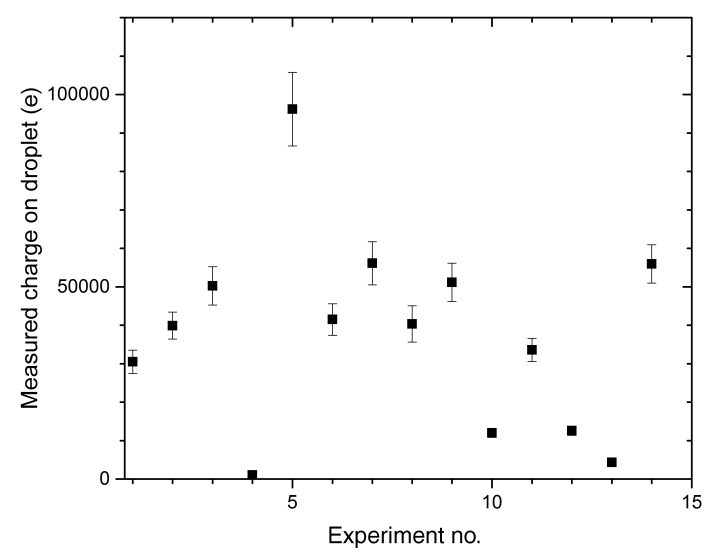

Figure 2. Measured elementary charge on droplets at different times. Error bars represent uncertainties in charge measurement due to the uncertainty in the measurement of the vertical distance traveled by the droplet. The mean charge averaged over all the experiments is $39000 \mathrm{e}$ with a standard deviation of $20000 \mathrm{e}$.

\subsection{Experimental procedure}

The collision ice nucleation experiments were conducted at temperatures between 261 and $236 \mathrm{~K}$. Initially the chamber was evacuated for $5 \mathrm{~min}$ and then cooled to $258 \mathrm{~K}$. To cover the walls with a thin layer of ice, the chamber was filled with distilled water for $10 \mathrm{~s}$ and then flushed out. The chamber was again evacuated for $3 \mathrm{~min}$ and the detector was mounted. When the desired temperature of the chamber was reached, the droplet generator was turned on and droplets were observed in the detector. This blank experiment without aerosol particles was performed at each temperature in order to ensure that there is no droplet freezing without particles. After the blank experiments, the aerosol flow was turned on and the actual experiment was performed. After completing the experiment for one temperature, the temperature of the chamber was lowered in steps of 2 to $3 \mathrm{~K}$ until the homogeneous freezing temperature was reached.

\section{Experimental results}

Figure 3 shows the frozen fraction of droplets as a function of temperature for the investigated concentrations of the 200 and $400 \mathrm{~nm}$ silver iodide particles and residence times of $2 \mathrm{~s}$ (panels a, c) and $4 \mathrm{~s}$ (panels b, d). Error bars shown represent an uncertainty in the frozen fraction due to the classification (liquid or ice) uncertainty originating from the measurement errors of the IODE detector (Lüönd et al., 2010). As the chamber temperature was decreased, the frozen fraction started to rise and after reaching a certain value, it remained constant. The frozen fraction plateau is reached at about $245 \mathrm{~K}$. A frozen fraction of 1 is not reached even for the lowest investigated temperature of $238 \mathrm{~K}$. According to classical nucleation theory, homogeneous nucleation be- 


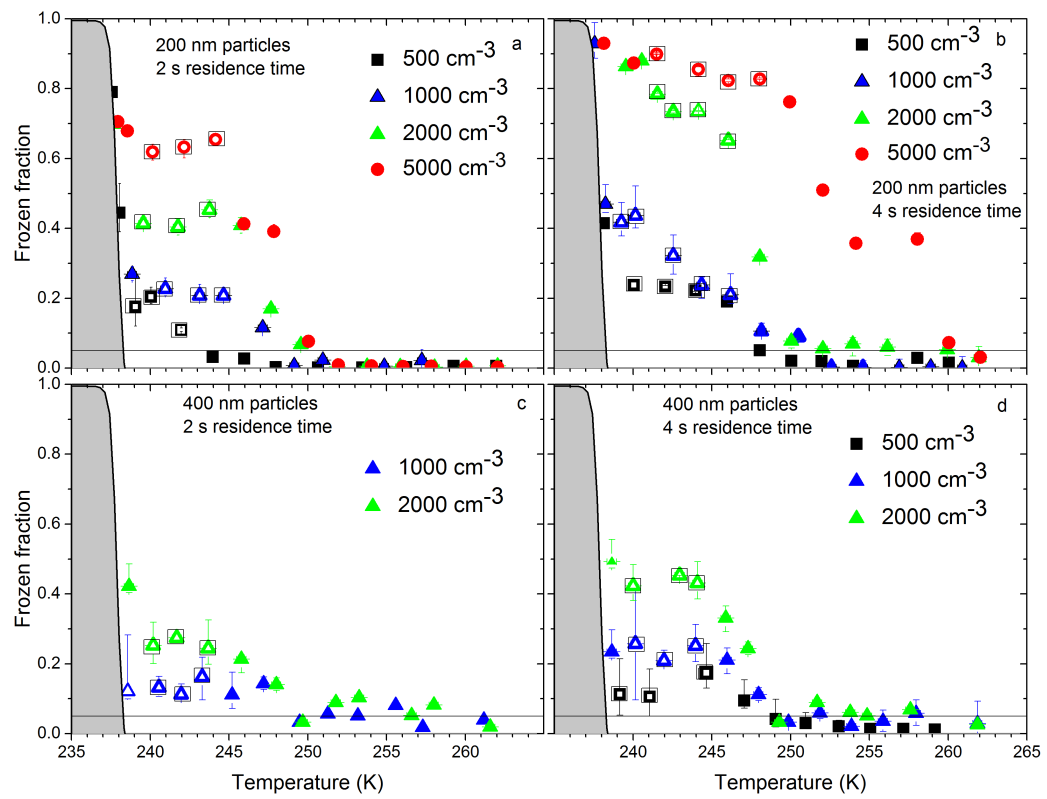

Figure 3. Frozen fraction against chamber temperature for droplet residence times of $2 \mathrm{~s}(\mathbf{a}, \mathbf{c})$ and $4 \mathrm{~s}(\mathbf{b}, \mathbf{d})$ for different concentrations of silver iodide and two different sizes $(200 \mathrm{~nm}(\mathbf{a}, \mathbf{b})$ and $400 \mathrm{~nm}(\mathbf{c}, \mathbf{d}))$. The gray shaded area indicates homogeneous freezing from blank experiments. The horizontal black line indicates the detection limit of the detector determined from the blank experiments. Open symbols indicate the experiments used for the calculation of collision efficiencies.

comes effective only for $T<238 \mathrm{~K}$ (e.g., Ickes et al., 2015). We assume that for $T<245 \mathrm{~K}$, heterogeneous freezing on AgI particles is so efficient that each collision of a particle with a droplet leads to the immediate freezing of the droplet (freezing efficiency of 1) and the frozen fraction plateau is reached. For $T>245 \mathrm{~K}$, the probability of droplet freezing is $<1$, and the collision of a particle with a droplet does not necessarily induce freezing. For $T<245 \mathrm{~K}$, frozen fractions increase with increasing particle concentration from 500 to $5000 \mathrm{~cm}^{-3}$ without reaching a value of 1 and they are higher for $4 \mathrm{~s}$ residence time than for $2 \mathrm{~s}$ residence time. This is in accordance with immediate contact freezing once the droplet has collected a particle. This limits contact freezing by the probability that a droplet actually captures a particle while it is falling through the chamber. If the freezing probability for $T<245 \mathrm{~K}$ is assumed to be 1 , this temperature range can be used to deduce collision efficiencies from our experimental data. We therefore define data points that correspond to unity freezing probability and use them to derive experimental collision efficiencies. These points are indicated by open symbols in black rectangles in Fig. 3. With our preparation method for AgI, the concentration of $800 \mathrm{~nm}$ diameter particles was too low to keep a constant concentration during the time needed for an experiment. To derive collision efficiency for $800 \mathrm{~nm}$ particles, we therefore used kaolinite particles. The experimental setup for these measurements was the same as for AgI except for the particle generation method, which is described in Nagare et al. (2015). Figure 4, shows the evolu- tion of the frozen fraction as a function of the residence time in the chamber calculated as

$F F=1-e^{-E_{\exp } K_{\mathrm{geo}} C_{\mathrm{par}} t}$,

where $K_{\text {geo }}$ is the geometrical area swept out by the droplet per unit time $t, C_{\mathrm{par}}$ is the particle concentration and $E_{\exp }$ is the collision efficiency that fits the experimental results best. $K_{\text {geo }}$ was simulated for each $0.01 \mathrm{~s}$ time step to take the size change in the droplet and change in terminal velocity into account. Since the collision efficiency should be the same for all concentrations and not depend on residence time, $E_{\text {exp }}$ was determined by simultaneously minimizing the difference between the mean values of frozen fraction indicated by the symbols in Fig. 4 and the frozen fraction calculated with Eq. (19). In our experiment the droplets evaporate slowly, which decreases the $K_{\text {geo }}$ over time. We take the average of collision efficiency over the residence time in the chamber; thus, small changes in $K_{\text {geo }}$ are also taken into account. $K_{\text {geo }}$ decreases almost linearly with highest values at the first time step $\left(\approx 1.06 \times 10^{-3} \mathrm{~cm}^{3} \mathrm{~s}^{-1}\right)$ and the lowest one in the last $\left(\approx 1.042 \times 10^{-3} \mathrm{~cm}^{3} \mathrm{~s}^{-1}\right)$. This yielded a value of $E_{\text {exp }}=0.13$ for $200 \mathrm{~nm}$ particles, in reasonable agreement with all data points, taking experimental uncertainties into account. To show the sensitivity of the frozen fraction to the assumed collision efficiency, curves for $E=0.02$ (according to the theoretical formulation of $\mathrm{P} 05$ and W78) are also given in Fig. 4 as dashed lines. 


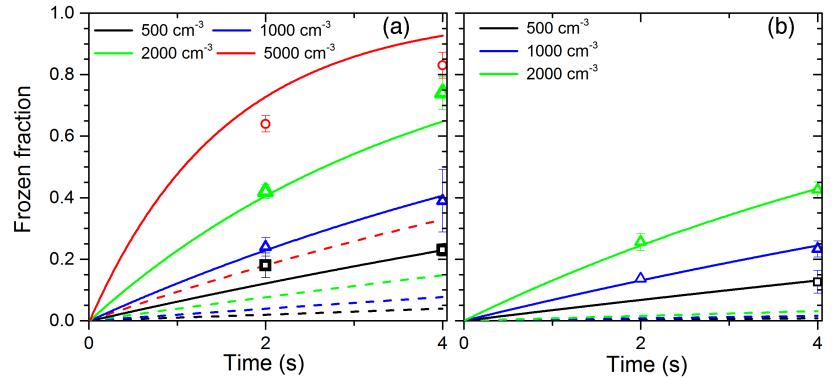

Figure 4. Evolution of the frozen fraction as a function of the residence time in the chamber calculated for different particle concentrations from 500 to $5000 \mathrm{~cm}^{-3}$. Solid lines are calculated with Eq. (19) assuming a collision efficiency $E_{\exp }=0.13$ and dashed lines for $E=0.02$ for $200 \mathrm{~nm}$ particle in (a), while in (b) $E_{\exp }=$ 0.07 and $E=0.004$ for $400 \mathrm{~nm}$ particles. Symbols and uncertainty bars give the average and standard deviation of the frozen fraction plateau values indicated by open symbols in Fig. 3 .

\section{Comparison of the different formulations of collision efficiency}

Figure 5 shows the different contributions to the total collision efficiency of an $80 \mu \mathrm{m}$ droplet as a function of AgI particle diameter calculated with the theoretical expressions of Sect. 2 for the experimental conditions of CLINCH, which is kept at ice saturation for $T=245 \mathrm{~K}$. Temperature and vapor pressure gradients between the droplet surface and the surrounding air are calculated as is the slow evaporation of the droplet along its path through the chamber in time increments of $0.01 \mathrm{~s}$. Mean collision efficiencies for the whole chamber length are obtained by averaging over the individual $0.01 \mathrm{~s}$ increments. In this simulation, the droplet has a diameter of $80 \mu \mathrm{m}$ when it enters the chamber and shrinks to $79 \mu \mathrm{m}$ at the end of the chamber. This slow evaporation induces a temperature gradient between the surrounding air and the droplet $\left(T_{\mathrm{a}}-T_{\mathrm{s}}=0.3 \mathrm{~K}\right)$, leading to thermophoresis. AgI particles have a density of $5600 \mathrm{~kg} \mathrm{~m}^{-3}$ and one elemental charge since they passed through a DMA for size selection. Major uncertainties are associated with the charge of the droplets. For the calculations shown in Fig. 5, a charge of $50000 \mathrm{e}$ of opposite sign to that of the particles was assumed. Panel a of Fig. 5 shows the collision efficiencies of Brownian diffusion, interception and impaction for the formulations in P05, described in Sect. 2.2.1, and S83, described in Sect. 2.2.2. The formulations for Brownian diffusion and interception by $\mathrm{P} 05$ and $\mathrm{S} 83$ show a very similar particle size dependence, but the values using S83 are about a factor of 3 higher for $E_{\mathrm{Br}}$ and even 1 order of magnitude higher for $E_{\text {int }}$. While the formulations of P05 are derived theoretically from a resolved flow field, S83 used dimensional analysis coupled with experimental results. Although the formulation of P05 explicitly takes the increased collision efficiency for a flow around a liquid droplet compared with a flow around a solid

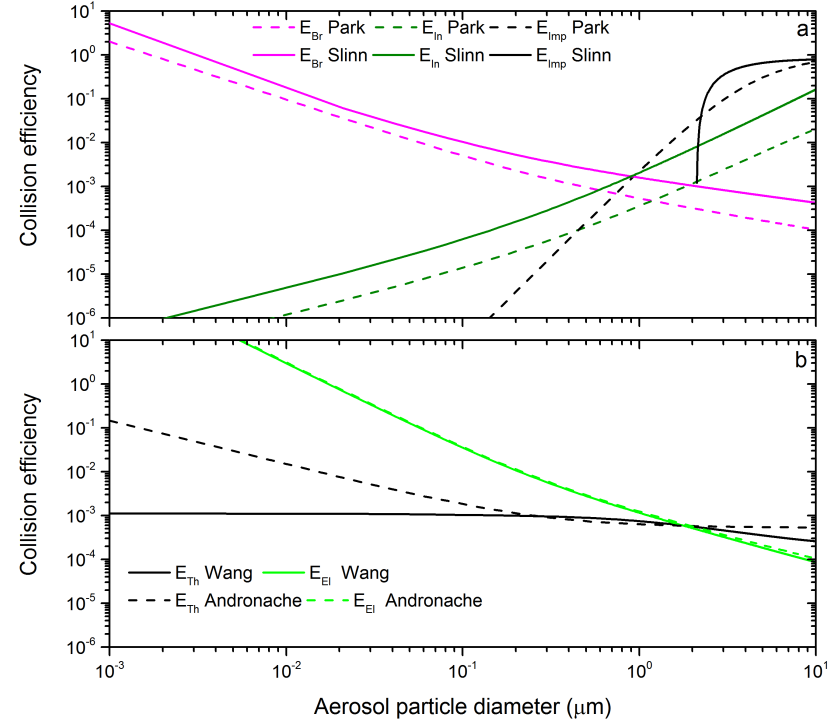

Figure 5. Calculated collision efficiency for a droplet of $80 \mu \mathrm{m} \mathrm{di-}$ ameter as a function of aerosol particle diameter at a temperature of $245 \mathrm{~K}$ and ice saturation. The contributions of Brownian motion, interception and impaction are shown in (a) for the formulations by Park et al. (2005) (P05) and Slinn (1983) (S83). The contributions for thermophoresis and electrophoresis are shown in (b) for the formulations by Andronache et al. (2006) (A06) and Wang et al. (1978) (W78).

sphere into account, it yields lower collision efficiencies than the one by S83. The formulation of S83 crucially depends on the accuracy of the experiments forming the basis for the dimensional analysis. $E_{\text {imp }}$ using S83 drops off to 0 for a particle diameter $d_{\mathrm{p}}<2 \mu \mathrm{m}$ because of the critical Stokes number in the formulation of impaction below which the impaction of particles on droplets is 0 . For particles smaller than $0.1 \mu \mathrm{m}$, Brownian diffusion is the most dominant mechanism and for particles above $1 \mu \mathrm{m}$ diameter, impaction dominates for the formulation of P05. For the $200 \mathrm{~nm}$ particles used in our experiments the collision efficiency by Brownian diffusion is more than 1 order of magnitude more efficient than interception and impaction.

Panel b of Fig. 5 shows the collision efficiencies due to individual contributions for thermophoresis and electrophoresis. Diffusiophoresis results in a repulsive force rendering the collision efficiency negative for the formulation of A06 $\left(\approx-10^{-4}\right)$ and too small to be represented in Fig. 5 using W78 $\left(\approx 10^{-28}\right)$. While collision efficiencies by electrophoresis are almost identical, considerable differences for thermophoresis in particle size dependence can be found comparing the formulations A06 and W78. A06 predicts a decrease in collision efficiency for increasing particle size whereas W78 shows hardly any dependence on aerosol particle diameter. The expression by W78 is formulated for the slip regime $(K n<0.1)$ and applies to larger particles (Leong et al., 1982). The expression of A06 applies to the free molec- 


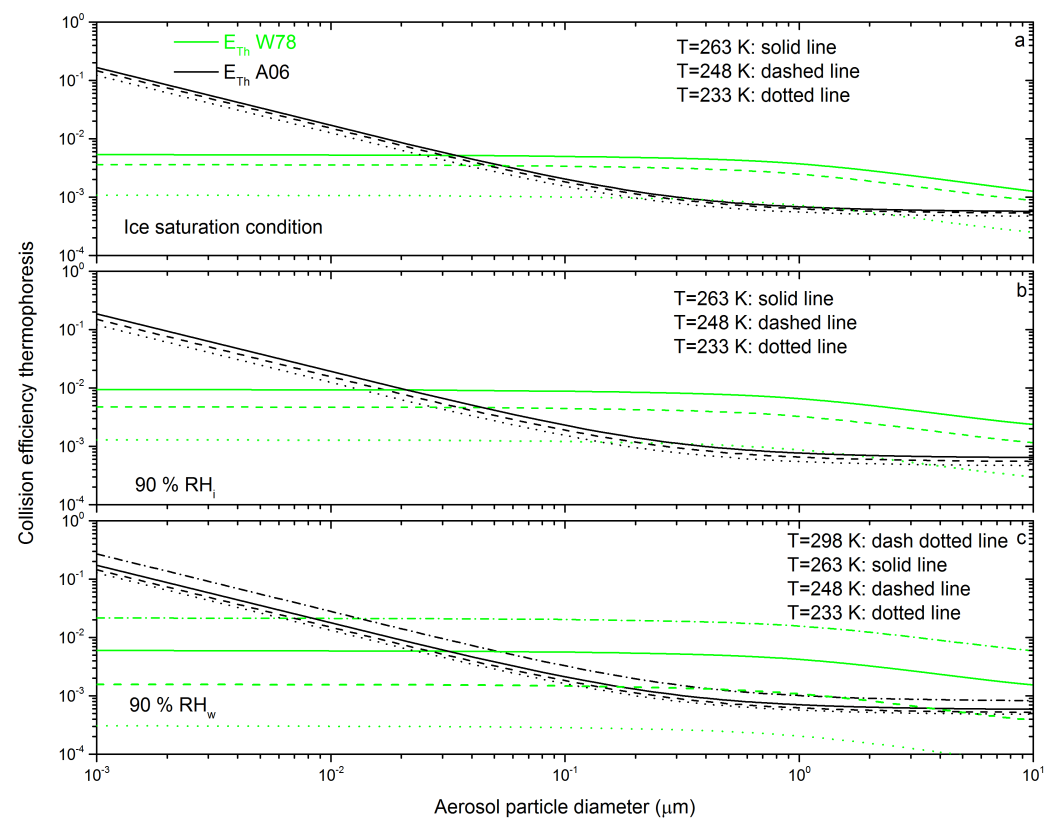

Figure 6. Dependence of thermophoresis on aerosol particle diameter following Andronache et al. (2006) (A06) and Wang et al. (1978) (W78) for a droplet of $80 \mu \mathrm{m}$ diameter: (a) at ice saturation for temperatures of 263, 248 and $233 \mathrm{~K}$; (b) at $90 \%$ relative humidity with respect to ice; (c) at $90 \%$ relative humidity with respect to water.

ular regime $(K n>10)$ and small particles (Slinn and Hales, 1971). Electrophoresis contributes the most for the smallest of the aerosol particles, i.e., particles with diameters in the range of $1 \mathrm{~nm}$ to $0.1 \mu \mathrm{m}$.

\subsection{Temperature dependence of thermophoretic collision efficiency}

Panel a of Fig. 6 shows the dependence of the collision efficiency due to thermophoresis for $T=263,248$ and $233 \mathrm{~K}$, keeping the other parameters the same as used for Fig. 5. As the temperature decreases the effect of thermophoresis also decreases because the evaporation rate of the droplet decreases and therefore also the temperature gradient decreases. On the other hand, the collision efficiency by thermophoresis is also influenced by the decreasing relative humidity with decreasing temperature from $90.6 \%$ at $263 \mathrm{~K}$ to $78.2 \%$ at $248 \mathrm{~K}$ and finally to $67.8 \%$ at $233 \mathrm{~K}$ because the chamber is kept at ice saturation conditions. To separate the influence of temperature from that of relative humidity, panel $b$ of Fig. 6 shows the dependence of thermophoresis on temperature with the environmental relative humidity with respect to ice at $90 \%$ and panel c shows this dependence with the environmental relative humidity with respect to water at $90 \%$. In addition, curves at $T=298 \mathrm{~K}$ are also shown as dash dotted lines in panel $\mathrm{c}$ for a better comparison with other studies. The temperature dependence of W78 is much stronger than the one of A06. Since for our experimental settings, diffusiophoresis results in a repulsive force rendering the collision efficiency negative or 0 , we do not show the tem- perature dependence of diffusiophoresis here. The combined description of thermophoretic and diffusiophoretic forces indicate that for our experimental conditions of evaporating droplets in the presence of rather small aerosol particles, thermophoresis should exceed diffusiophoresis (Slinn and Hales, 1971). However, disagreement still exists between experiments and model predictions concerning the prevalent forces as a function of particle radius (Santachiara et al., 2012; Prodi et al., 2014).

\subsection{Charge dependence of electrophoresis}

Figure 7 shows the droplet charge dependence of electroscavenging for the formulations of A06 and W78. Calculations are shown for droplet charges of 5000, 10000 , and $50000 \mathrm{e}$ and a particle charge of $1 \mathrm{e}$. All other parameters are the same as for Fig. 5. Charges on droplets and particles are of opposite sign. Both formulations show the same charge and particle size dependence with a strong increase in collision efficiencies with increasing droplet charge and decreasing particle size. If the charges of droplets and particles were of the same sign, particles would be repulsed from the droplets and the collision efficiency would effectively be 0 , since the formulations of A06 and W78 both assume point charges located in the middle of the particles and droplets and do not take into account image charge effects. When aerosol particles come close enough to water droplets, image charges on the conducting droplets can lead to attraction even if the charges on the particle and on the droplet are of the same sign (Tinsley et al., 2000). When the radial component of the flow car- 


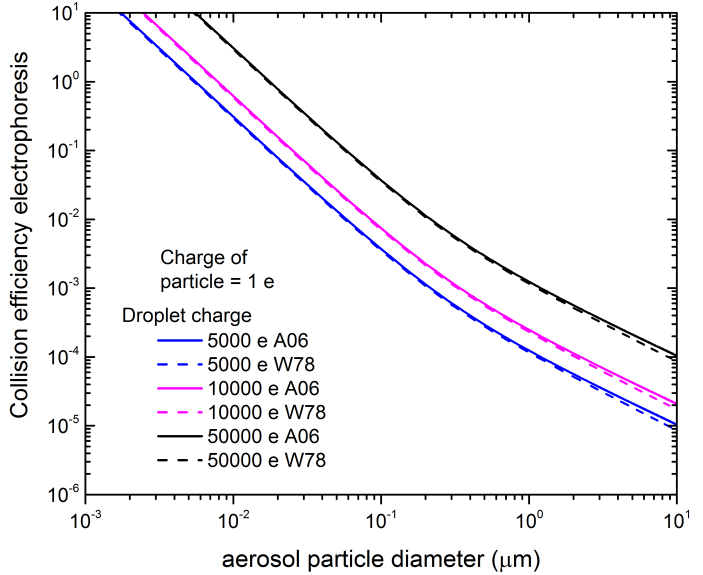

Figure 7. Dependence of electrophoresis on droplet charges for the formulations of Andronache et al. (2006) (A06) and Wang et al. (1978) (W78). The legend indicates the elementary charge on the droplets. The aerosol particles carry one elementary charge.

ries the particle towards the droplet as fast as the particle is repulsed, then the particle will pass through the distance of maximum repulsion and in most cases collide with the droplet, as the image forces increase very rapidly at close distance. Tinsley et al. (2000) show in their Fig. 5c and d that for particles with diameters $>500 \mathrm{~nm}$ and charges of 5500 e electroscavenging by droplets with $84 \mu \mathrm{m}$ diameter and a charge of $500 \mathrm{e}$, does not depend on whether the charges of droplets and particles are of the same or opposite sign. Particles with diameters $<200 \mathrm{~nm}$ are strongly repulsed from the droplets when their charge is of the same sign as the droplet charge and strongly attracted when the charges are of opposite sign. For particles with diameters of $200 \mathrm{~nm}$, collision efficiencies are larger by a factor of 2 in the case of opposite sign than in the case of the same sign. Moreover, for our experimental situation, image charges will diminish the difference between electroscavenging between particles and droplets with like and opposite charges. However, the effect might be smaller because the AgI particles carry only one elementary charge, resulting in a smaller image force compared to the situation shown in Tinsley et al. (2000), and the droplets are highly charged, increasing the radius of repulsion that has to be overcome until attractive image forces set in.

\subsection{The total collision efficiency $\boldsymbol{E}_{\text {Tot }}$}

Figure 8 shows the total collision efficiency for different combinations of the theoretical formulations for the same experimental conditions as in Fig. 5. All combinations of collision efficiencies are dominated by electrophoresis for particle diameters $<100 \mathrm{~nm}$ and by impaction for diameters $>2 \mu \mathrm{m}$. In this range Brownian diffusion, electrophoresis and thermophoresis contribute significantly to the total collision efficiency. For $200 \mathrm{~nm}$ particles, the total collision

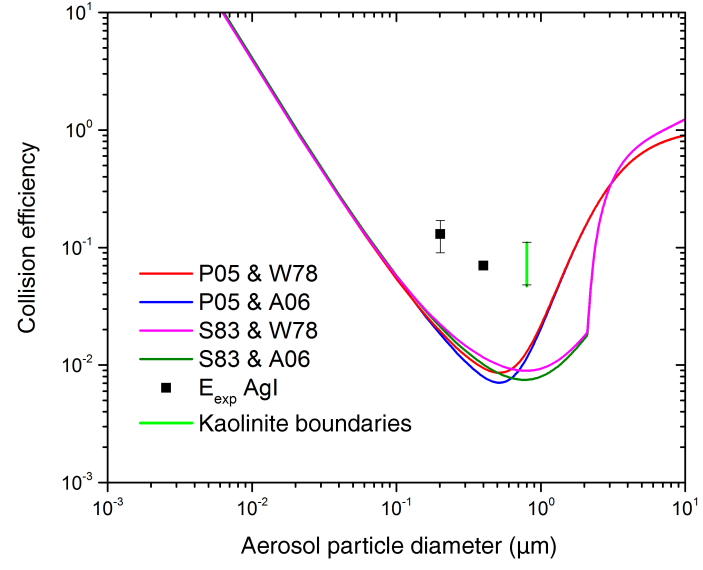

Figure 8. Total collision efficiency for a droplet of $80 \mu \mathrm{m}$ diameter as a function of aerosol particle diameter at $245 \mathrm{~K}$ and ice saturation. The total collision efficiency is the sum of all individual contributions. The experimentally determined collision efficiency for 200 and $400 \mathrm{~nm}$ silver iodide particles colliding with $80 \mu \mathrm{m}$ water droplets is shown by squares. The error bars represent the uncertainty level derived by optimizing the collision efficiency to the upper and lower limits of experimentally determined frozen fractions shown by the symbols in Fig. 4. The green line shows the upper and lower bound for $800 \mathrm{~nm}$ kaolinite particles. Since the assumption of a freezing efficiency of 1 is not valid at any temperature for kaolinite, no plateau region is available for evaluation. We can therefore only give upper and lower boundaries of collision efficiency for these particles.

efficiency is lowest (0.01) for the combination P05 and A06 and highest $(0.02)$ for the combination S83 and W78. In our approach total collision efficiencies are obtained by adding up collision efficiencies of the different processes with values $\geq 0$. Negative collision efficiencies were not considered since they lack physical meaning. In trajectory calculations (Tinsley, 2010; Tinsley and Leddon, 2013), the simultaneous action of the different forces on the particle can be investigated. These calculations show that, e.g., for small particles, the total collision efficiency can be lower than the one by Brownian diffusion alone when Brownian diffusion is diverted by the repulsion of particles carrying charges of the same sign as the droplet (Tinsley et al., 2006). Table 1 shows the dependence of the total collision efficiency on droplet and particle sizes used in the experiments for P05 and W78 (red line in Fig. 8). Other formulations show similar variations in total collision efficiency. In addition, it lists the sensitivity of the total collision efficiency to the density of the particle and variation in atmospheric pressure. For both these parameters, the calculated collision efficiency sensitivity is found to be negligible. It should be noted that impaction collision efficiency in S83 is normalized by the density of the particle, but this effect can only be seen for particles larger than $2 \mu \mathrm{m}$. The listed particle densities are the ones of silver iodide $\left(5600 \mathrm{~kg} \mathrm{~m}^{-3}\right)$ and potassium nitrate $\left(2100 \mathrm{~kg} \mathrm{~m}^{-3}\right)$. 
Table 1. Dependency of collision efficiency on droplet diameter, particle density and atmopheric pressure.

\begin{tabular}{|c|c|c|c|}
\hline \multirow[t]{2}{*}{ Parameter } & \multicolumn{3}{|c|}{ Particle diameter $(\mathrm{nm})$} \\
\hline & 200 & 400 & 800 \\
\hline \multicolumn{4}{|c|}{ Droplet diameter $(\mu \mathrm{m})$} \\
\hline 77 & 0.0158 & 0.0082 & 0.008 \\
\hline 80 & 0.0134 & 0.007 & 0.0074 \\
\hline 83 & 0.0115 & 0.0061 & 0.0069 \\
\hline \multicolumn{4}{|c|}{ Density of particle $\left(\mathrm{kg} \mathrm{m}^{-3}\right)$} \\
\hline 2100 & 0.0134 & 0.007 & 0.0074 \\
\hline 5600 & 0.0134 & 0.007 & 0.0074 \\
\hline \multicolumn{4}{|c|}{ Atmospheric pressure $(\mathrm{hPa})$} \\
\hline 960 & 0.0134 & 0.007 & 0.0074 \\
\hline 1000 & 0.0135 & 0.007 & 0.0074 \\
\hline
\end{tabular}

\section{Comparison with previous experimental work}

A direct comparison of our experimental results with other measurements of collision efficiencies is not possible because collision efficiency is sensitive to many parameters, which are only partly the same in different experiments. Important parameters that determine the collision efficiency are droplet and particle sizes, charges on droplets and particles, relative humidity and temperature. Laboratory studies summarized by Wang and Pruppacher (1977) and Ladino et al. (2011b) have all been performed at or close to room temperature. In a critical review, Wang and Pruppacher (1977) criticize most older studies for insufficient control of relative humidity, insufficient control or knowledge of charges on droplets and particles, and the use of large droplets so that the terminal velocity is not reached during the experiment. In the following, the relevant studies that can be compared with our data are summarized. Lai et al. (1978) investigated collection efficiency of $\mathrm{AgCl}$ aerosol particles by freely falling water droplets in nitrogen. For 300, 500, and $900 \mathrm{~nm}$ diameter particles scavenged by $1.24 \mathrm{~mm}$ diameter droplets, they measured collection efficiencies of $0.107,0.016$ and 0.045 , respectively. These results are in agreement with ours, considering the larger particle and droplet sizes employed by Lai et al. (1978). When $1.24 \mathrm{~mm}$ diameter droplets were charged with surface charge densities of $-0.7 \times 10^{10}$ to $-3.0 \times 10^{10} \mathrm{Ccm}^{-2}$ and $+0.8 \times 10^{10}$ to $+3.1 \times 10^{10} \mathrm{Ccm}^{-2}$, the collection efficiency for $480 \mathrm{~nm}$ diameter particles increased from 0.017 to $0.023-0.067$ irrespective of the sign of the charge. This increase illustrates the effect of image charge that is also expected to influence our collision efficiencies. Byrne and Jennings (1993) and Barlow and Latham (1983) obtained collision efficiencies in reasonable agreement with Lai et al. (1978) for similar experimental conditions. Radke et al. (1980) performed airborne measurements of aerosol size distributions before and after rain or snow showers in aged air masses and found good agreement with theoretical calculations for particles $\geq 1 \mu \mathrm{m}$ in diameter, where inertial impaction dominates scavenging. For the submicron aerosol particles the Greenfield gap was narrower than predicted by theory. Measured scavenging collection efficiencies typically ranged from 0.1 to 0.7 for $200 \mathrm{~nm}$ diameter particles, which is in general agreement with our results, and dropped to $<0.05$ in the size range $400-1000 \mathrm{~nm}$. Beard (1974) determined collection efficiencies of uncharged $700-900 \mathrm{~nm}$ diameter particles with $0.40-0.85 \mathrm{~mm}$ diameter droplets with charges of $10^{-5}, 10^{-4}$, and $10^{-3}$ esu (1-100 fC) at $99 \% \mathrm{RH}$ and a temperature of $24^{\circ} \mathrm{C}$. They found increasing collection efficiencies with increasing droplet charge of $0.5 \times 10^{-4}$ $3.7 \times 10^{-4}$ for $10^{-5}$ esu, $2.3 \times 10^{-4}-11.6 \times 10^{-4}$ for $10^{-4} \mathrm{esu}$, and $12.2 \times 10^{-4}-16.1 \times 10^{-4}$ for $10^{-3}$ esu, again illustrating the influence of image charge. Their considerably lower values compared with ours can be partly ascribed to the larger particle and droplet sizes and partly to the absence of phoretic forces. The increase in collection efficiency due to phoretic forces can be seen comparing with the results from Lai et al. (1978), performed at low RH, which are 2 orders of magnitude larger for similar particle and droplet sizes. Wang and Pruppacher (1977) determined collection efficiencies for $500 \mathrm{~nm}$ diameter indium acetylacetonate particles collected by water droplets at $23 \% \mathrm{RH}$ and $22^{\circ} \mathrm{C}$. They observed a collection efficiency of $1.8 \times 10^{-2}$ for $340 \mu \mathrm{m}$ diameter droplets with charges of $1.2 \times 10^{-3}$ esu (15 e). This value, which is lower than ours, can be explained by the larger particle and droplet size and the lower charge in the experiment of Wang and Pruppacher (1977). Ladino et al. (2011a) determined collision efficiencies for aerosol particles scavenged by cloud droplets in CLINCH using $26 \mu \mathrm{m}$ diameter droplets. They exposed freely falling water droplets at $298 \mathrm{~K}$ and $90 \% \mathrm{RH}$ to an aerosol consisting of lithium metaborate particles with diameters between 0.1 and $0.66 \mu \mathrm{m}$ and observed collision efficiencies of between $E=0.08-1.75$. $E_{\text {tot }}>1$ is obtained because of the high efficiency of Brownian diffusion for small particles. Figure 9 shows that their experimental results are in agreement with the theoretical predictions. Ardon-Dryer et al. (2015) determined collision efficiencies between polystyrene latex (PSL) spheres with radii from 0.125 to $0.475 \mathrm{~nm}$ and $43 \mu \mathrm{m}$ diameter droplets charged with $400 \pm 40 \mathrm{e}$. Collision efficiencies ranged from $5.7 \times 10^{-3}$ to $8.6 \times 10^{-3}$ for $\mathrm{RH}=15 \%$ and from $6.4 \times 10^{-3}$ to $2.2 \times 10^{-2}$ at $88 \% \mathrm{RH}$. These values are lower than the ones reached in this study, which may be explained by the lower charge on the PSL spheres. 


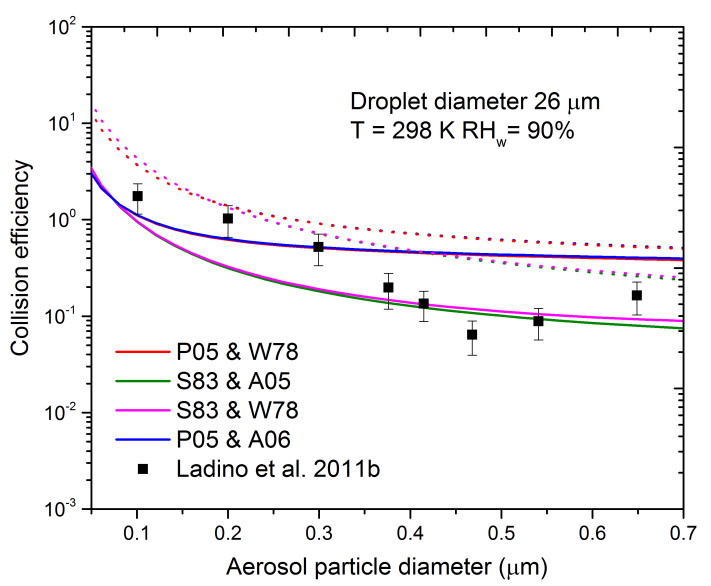

Figure 9. Total collision efficiency for a droplet of $26 \mu \mathrm{m}$ diameter as a function of aerosol particle diameters at a temperature of $298 \mathrm{~K}$ and $90 \%$ relative humidity with respect to water. The black squares indicate the measured collision efficiency by Ladino et al. (2011a). We have assumed charges of $10000 \mathrm{e}$ (solid lines) and $50000 \mathrm{e}$ (dotted lines).

\section{Discussion}

\subsection{Discrepancies between theoretical and experimentally derived collision efficiencies}

The experimentally derived collision efficiencies are almost 1 order of magnitude higher than the theoretical ones. It is unlikely that the experimentally derived ones are too high by this amount. The assumption that every collision leads to droplet freezing can only result in collision efficiencies that are too high. A conceivable process that would result in an overestimation of the collision efficiency could be that droplet freezing would influence the velocity of the droplets in such a way that frozen droplets collide with liquid ones. However, considering the sequence of frozen and liquid droplets, such a bias does not seem to exists. Brownian diffusion is the main collision mechanism for small particles in the absence of charges and one of the dominating contributions to the total collision efficiencies for the $200 \mathrm{~nm}$ diameter particles investigated in this study. The formulation of S83 predicts higher collision efficiencies than the one of P05 for Brownian diffusion and combinations with S83 for total collision efficiencies yield higher values. However, it is unlikely that uncertainties in the theoretical formulations of this process can account for the total discrepancy between experimentally derived and calculated collision efficiencies. Contributions of impaction and interception to total collision efficiencies are more than 1 order of magnitude lower than the one of Brownian diffusion, and therefore uncertainties in these formulations are not likely to fill the gap between experimentally derived and calculated collision efficiencies. The assumption that the charge on the droplet is $50000 \mathrm{e}$ and of opposite sign to the one on the particles results in the highest expected value for collision efficiencies due to electric forces. Accounting for image forces would only increase collision efficiencies in the case of the same charges on particles and droplets. The processes with the highest uncertainties are the ones arising from thermophoretic and diffusiophoretic forces. While diffusiophoresis leads to a repulsive force and does not contribute to the total collision efficiencies under our experimental conditions of evaporating droplets, thermophoresis is attractive and a dominating contribution. In the combined treatment of electrical, thermophoretic and diffusiophoretic forces, collection efficiencies can be lower than when efficiencies are treated separately and added up. In trajectory calculations (Zhou et al., 2009) Brownian motion, electrical and phoretic processes are treated together. Since the diffusiophoretic force of an evaporating droplet is repulsive, it can counteract attraction by thermophoresis and Brownian motion. A study on the simultaneous effect of phoretic processes performed by Slinn and Hales (1971) showed that thermophoresis dominates diffusiophoresis for evaporating droplets in quasi-steady state conditions for vapor diffusion and heat conduction. Similarly, the same charges on particles and droplets will divert particles away from the droplets at distances where mirror charges are too weak to lead to attraction and decrease the collision efficiency (Tinsley et al., 2000). For the calculation of collision efficiencies spherical particle shapes have been assumed. This assumption is valid for liquid or glassy particles but not for solid ones, which have a complex morphology with significant deviations from sphericity. The drag on a nonspherical particle depends on its orientation, which in turn is affected by shear in the flow field. In a theoretical study, Leong et al. (1985) estimated the effects of oblate and prolate particle rotation in shear flow and the shape dependency of the thermophoretic force of evaporating $30 \mu \mathrm{m}$ radius droplets. The results indicate that the orientation effects of the shear flow will tend to decrease the thermophoretic force on the particle toward the drop surface in the size regime where phoresis dominates because the nonspherical particle aligns itself with the streamlines and the velocity component of the phorestic force is minimized. Foss et al. (1989) investigated the collection of uncharged prolate spheroidal aerosol particles by $30 \mu \mathrm{m}$ radius collector droplets. They found that such particles can be captured on the downstream side of the collector in the absence of attractive forces in contrast to the case of spherical particles. In the case of prolate spheroidal aerosol particles collected by charged $30 \mu \mathrm{m}$ radius droplets, the collision efficiencies for particles having large aspect ratios are significantly lower than those for spherical particles when the Coulomb force is dominant. These studies indicate that deviations from particle sphericity decrease collision efficiencies for the experimental conditions of our study and cannot account for the discrepancy between measured and calculated collision efficiencies. The largest uncertainties are associated with the theoretical description of phoretic processes at low temper- 
atures. It might be necessary to reassess these to obtain expressions that are in better agreement with experiments.

\subsection{Implications for contact freezing}

The efficiency of contact freezing depends on the efficiency of the collision process and the ability of the particle to act as INP. The most important heterogeneous ice nuclei identified in the atmosphere so far are mineral dusts. Size distributions of mineral dusts depend on the age of the air mass because larger particles are removed by gravitational settling. Mineral dust particles cover a large size range from 0.1 to $100 \mu \mathrm{m}$ (Tegen and Schepanski, 2009; Maring et al., 2003). In the coupled aerosol-climate model ECHAM5-HAM, which was used to investigate heterogeneous contact and immersion freezing, the mineral dust aerosol is represented by two lognormal modes with mass-median radii of 0.37 and $1.75 \mu \mathrm{m}$ (Lohmann and Diehl, 2006; Hoose et al., 2008). Small particles collide with droplets mainly due to Brownian diffusion; large ones do so due to impaction. The predicted number of collisions varies by up to a factor of 3 for Brownian diffusion and impaction depending on the mathematical formulation that one chooses. Most importantly, in the highly relevant size range for ice nucleation on mineral dusts from $0.5-2 \mu \mathrm{m}$, calculated collision efficiencies are strongly reduced when a critical Stokes number is included in the formulation for impaction. In updrafts within clouds, a slight supersaturation typically persists, directing particles away from droplets due to thermophoresis, which is only partly compensated for by attraction due to diffusiophoresis. In downdrafts or when dry air is entrained in clouds, droplet evaporation mostly occurs at the cloud top and close to the edges of cumuli, which is the region where first ice in clouds is indeed observed (Young, 1974). Under such conditions, thermophoresis leads to attraction and may contribute significantly to the collision efficiency in the size range $0.1-2 \mu \mathrm{m}$. The two formulations for thermophoresis are very different in terms of particle size and temperature dependence. This term has to be reassessed to improve estimates of contact nucleation in models. In addition electric forces act on the particles, which may significantly contribute to the overall collision efficiency. Evaporating cloud droplets and aerosol particles released from evaporated droplets from the same region of the cloud are supposed to have like charges (Tinsley and Leddon, 2013). For particles of sizes that act as INP, such as mineral dusts, the predominant effect of their charge, irrespective of sign, is an increase in the collision rate due to the short-range electrical image charge attraction (Tinsley and Leddon, 2013). Layer clouds such as stratocumulus and altostratus are weakly electrified, producing droplet charges in the consequent gradients of the electric field on the order of 100 e on $20 \mu \mathrm{m}$ diameter cloud droplets (Zhou et al., 2009). Thunderstorm clouds are strongly electrified (Tinsley and Leddon, 2013), with cloud droplets bearing elementary charges in the range of 10000-100000 e. Taking the effect of image charges into account will therefore increase the collision rate of particles with droplets even more. In summary, the collision efficiency of mineral dust particles with cloud droplets is most probably underpredicted in state-of-the-art aerosol-climate models, leading to an underestimation of the relevance of contact nucleation, especially in evaporating clouds.

\subsection{Implications for atmospheric aerosol scavenging}

Impaction scavenging of aerosol particles can occur in-cloud and below-cloud. Below-cloud scavenging leads to the removal of aerosol particles from the atmosphere between the cloud base and the ground due to precipitation. In addition to impaction scavenging, in-cloud scavenging also includes contributions from nucleation scavenging (Seinfeld and Pandis, 2006). Aerosol scavenging is usually described by the scavenging coefficient $\left(\mathrm{s}^{-1}\right)$ defined as the rate of aerosol removal (Chate et al., 2011). In field measurements, the scavenging coefficient is usually calculated from measurements of the change in aerosol size distribution with rainfall (Santachiara et al., 2012). For very small and very large particles, there is mainly an agreement with theoretical studies. However, theoretical parameterizations often underestimate observed scavenging coefficients by $1-2$ orders of magnitude for particles in the $0.2-2 \mu \mathrm{m}$ diameter range, where collection efficiencies are lowest. Theoretical models predict Brownian diffusion as the dominating scavenging process of particles with diameters $<0.2 \mu \mathrm{m}$ and inertial impaction as the main scavenging process for diameters $>2 \mu \mathrm{m}$. For aerosol scavenging in the particle diameter range of $0.2-2 \mu \mathrm{m}$, contributions from electric and phoretic forces are thought to be important. In the case of thermal equilibrium between the droplet and the environment, water vapor evaporation or condensation are the only factors determining the temperature gradient; thermophoresis and diffusiophoresis are supposed to act in opposite directions. However, in rain events, falling raindrops can have a different temperature from that of the ambient air and diffusiophoretic and thermophoretic forces will reinforce each other (Santachiara et al., 2012). Many theoretical studies on scavenging do not take phoretic forces into account, but even those which do are not able to explain the discrepancies between field and observed scavenging coefficients in the Greenfield gap (Santachiara et al., 2012). Most model parameterizations treat the collision processes separately and either assume that they act in series (Davenport and Peters, 1978) or calculate the total collision efficiency as the sum of individual collision efficiencies (Bae et al., 2009; Andronache et al., 2006). With this approach, the net effect of repulsive and attractive contributions of forces acting on particles cannot be taken into account correctly. Figures 5 and 6 show that the collision efficiency formulations of thermophoresis of W78 and A06 are vastly different. They are derived for large and small particles, respectively, but in most studies applied to the whole simulated particle size range. Moreover, the temperature dependency of the for- 
mulations by A06 and W78 is very different, indicating large uncertainties here, too. From this, it can be concluded that phoretic forces give important contributions to the scavenging of aerosol particles in the accumulation mode and are most probably also a main source of uncertainties in aerosol scavenging predictions.

\section{Summary and conclusions}

This study uses contact freezing experiments of freely falling $80 \mu \mathrm{m}$ diameter droplets exposed to an aerosol consisting of silver iodide particles. The chamber is kept at ice saturation in a temperature range of $236-261 \mathrm{~K}$, leading to slow evaporation of water droplets, which gives rise to thermophoresis and diffusiophoresis. Droplets and particles bear charges inducing electrophoresis. From the experimental results, collision efficiencies of 0.13 and 0.07 were derived for 200 and $400 \mathrm{~nm}$ diameter particles, respectively. In addition, an upper and lower bound for $800 \mathrm{~nm}$ kaolinite particles of 0.047-0.11 was derived. These values are compared with theoretical formulations, which yield values from 0.01 to 0.02 . Brownian diffusion, electrophoresis and thermophoresis contribute the most to these values. The presented theoretical schemes were developed and applied mostly for rain conditions at $T>0{ }^{\circ} \mathrm{C}$. Most experimental parameters are well constrained or show little sensitivity with respect to the resulting collision efficiencies and can therefore not account for the observed discrepancies at $T<0^{\circ} \mathrm{C}$. Comparisons of different theoretical formulations show differences within 1 order of magnitude in the accumulation mode. There are large differences between the formulations for thermophoresis from A06 and W78 regarding size and temperature dependence. For our experimental conditions, diffusiophoresis results in a repulsive force and does not contribute to the total collision efficiency. It can be expected that in a combined treatment of the forces acting on particles, the calculated total collision efficiency would even be lower. Collision efficiencies are important parameters needed to correctly represent contact freezing and aerosol scavenging in models. Thermophoresis and diffusiophoresis are supposed to give important contributions to the scavenging of aerosol particles in the accumulation mode but are most probably also the main sources of uncertainties in aerosol scavenging predictions. For ice nucleation in contact mode, an accurate description of collision efficiencies below $273 \mathrm{~K}$ is needed. Ice nucleating particles are most probably in the accumulation mode size range. For this size range collection efficiencies are lowest and associated with the largest uncertainties. More experimental data of collision efficiencies, especially at low temperatures, are needed to validate theoretical formulations. This is, to the authors' knowledge, the first data set of collision efficiencies acquired below $273 \mathrm{~K}$. More such experiments with different particle diameters are needed to improve the understanding of collision efficiencies. 


\section{Appendix A}

Table A1. List of symbols.

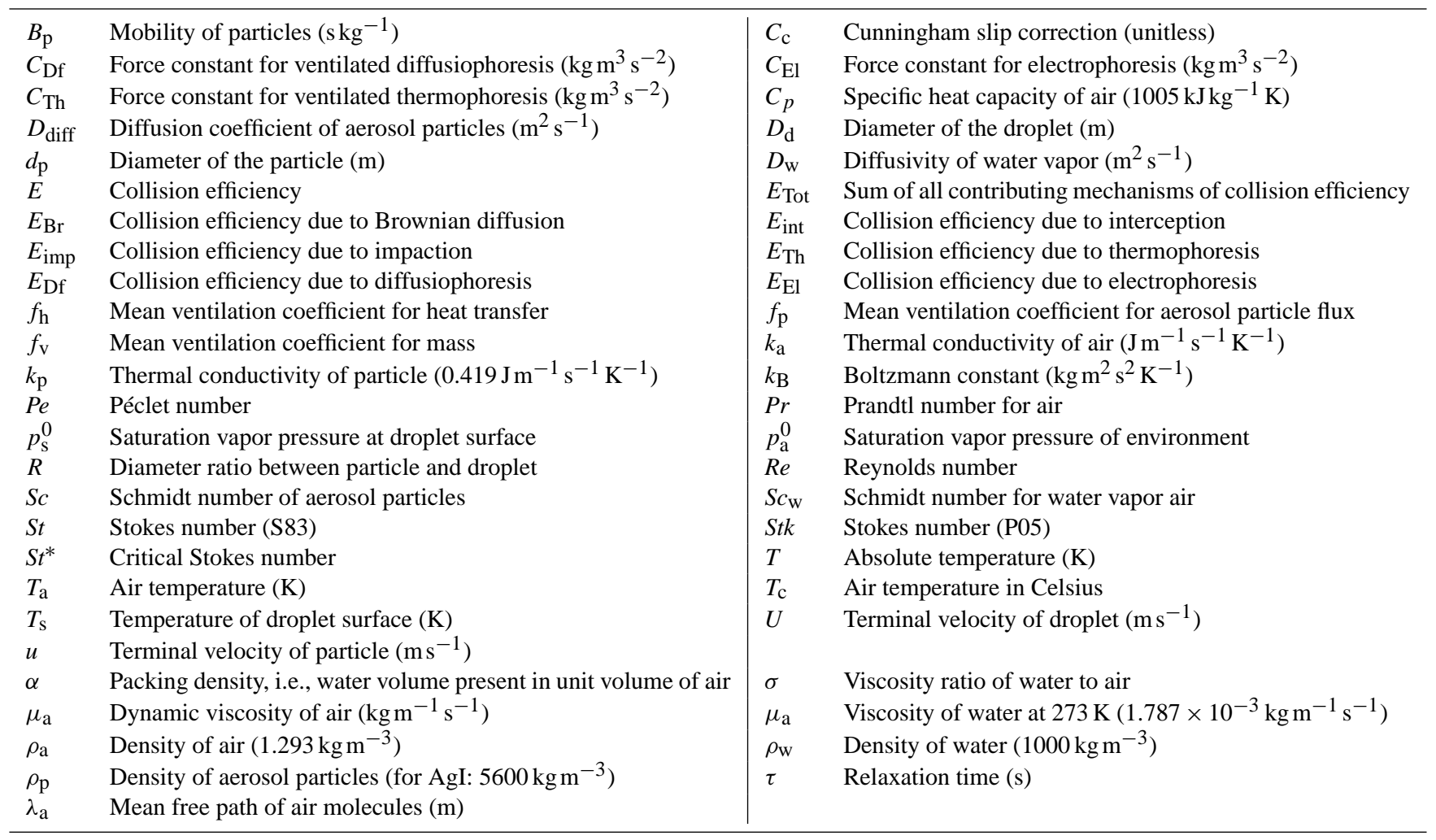


Author contributions. B. Nagare carried out the experiments and evaluations. B. Nagare and C. Marcolli prepared the manuscript. O. Stetzer supervised the laboratory work and U. Lohmann supervised the work overall.

Acknowledgements. This work was supported by the Swiss National Foundation, project 200020_150169. We thank Luis Ladino for providing data for Fig. 7 and Zamin Kanji, Dan Cziczo, Brian Tinsley, André Welti, Jan Henneberger and Joel Corbin for useful discussions.

Edited by: A. Nenes

\section{References}

Andronache, C.: Diffusion and electric charge contributions to below-cloud wet removal of atmospheric ultrafine aerosol particles, J. Aerosol Sci., 35, 1467-1482, doi:10.1016/j.jaerosci.2004.07.005, 2004.

Andronache, C., Grönholm, T., Laakso, L., Phillips, V., and Venäläinen, A.: Scavenging of ultrafine particles by rainfall at a boreal site: observations and model estimations, Atmos. Chem. Phys., 6, 4739-4754, doi:10.5194/acp-6-4739-2006, 2006.

Ardon-Dryer, K., Huang, Y.-W., and Cziczo, D. J.: Laboratory studies of collection efficiency of sub-micrometer aerosol particles by cloud droplets on a single-droplet basis, Atmos. Chem. Phys., 15, 9159-9171, doi:10.5194/acp-15-9159-2015, 2015.

Bae, S. Y., Jung, C. H., and Kim, Y. P.: Relative contributions of individual phoretic effect in the below-cloud scavenging process, J. Aerosol Sci., 40, 621-632, doi:10.1016/j.jaerosci.2009.03.003, 2009.

Barlow, A. K. and Latham, J.: A laboratory study of the scavenging of sub-micron aerosol by charged raindrops, Q. J. Roy. Meteor. Soc., 109, 763-770, doi:10.1002/qj.49710946205, 1983.

Beard, K. V.: Experimental and Numerical Collision Efficiencies for Submicron Particles Scavenged by Small Raindrops, J. Atmos. Sci., 31, 1595-1603, doi:10.1175/15200469(1974)031<1595:EANCEF>2.0.CO;2, 1974.

Byrne, M. and Jennings, S.: Scavenging of sub-micrometre aerosol particles by water drops, Atmos. Environ. A-Gen., 27, 20992105, doi:10.1016/0960-1686(93)90039-2, 1993.

Chate, D. and Pranesha, T.: Field studies of scavenging of aerosols by rain events, J. Aerosol Sci., 35, 695-706, doi:10.1016/j.jaerosci.2003.09.007, 2004.

Chate, D., Murugavel, P., Ali, K., Tiwari, S., and Beig, G.: Below-cloud rain scavenging of atmospheric aerosols for aerosol deposition models, Atmos. Res., 99, 528-536, doi:10.1016/j.atmosres.2010.12.010, 2011.

Croft, B., Lohmann, U., Martin, R. V., Stier, P., Wurzler, S., Feichter, J., Hoose, C., Heikkilä, U., van Donkelaar, A., and Ferrachat, S.: Influences of in-cloud aerosol scavenging parameterizations on aerosol concentrations and wet deposition in ECHAM5-HAM, Atmos. Chem. Phys., 10, 1511-1543, doi:10.5194/acp-10-1511-2010, 2010.

Davenport, H. and Peters, L. K.: Field studies of atmospheric particulate concentration changes during precipitation, Atmos. Environ., 12, 997-1008, doi:10.1016/0004-6981(78)90344-X, 1978.
DeMott, P. J., Prenni, A. J., Liu, X., Kreidenweis, S. M., Petters, M. D., Twohy, C. H., Richardson, M. S., Eidhammer, T., and Rogers, D. C.: Predicting global atmospheric ice nuclei distributions and their impacts on climate, P. Natl. Acad. Sci., 107, 11217-11222, 2010.

Durant, A. J. and Shaw, R. A.: Evaporation freezing by contact nucleation inside-out, Geophys. Res. Lett., 32, L20814, doi:10.1029/2005GL024175, 2005.

Fornea, A. P., Brooks, S. D., Dooley, J. B., and Saha, A.: Heterogeneous freezing of ice on atmospheric aerosols containing ash, soot, and soil, J. Geophys. Res., 114, D13201, doi:10.1029/2009JD011958, 2009.

Foss, J., Frey, M., Schamberger, M., Peters, J., and Leong, K.: Collection of uncharged prolate spheroidal aerosol particles by spherical collectors - I: 2D motion, J. Aerosol Sci., 20, 515-532, doi:10.1016/0021-8502(89)90098-0, 1989.

Greenfield, S. M.: Rain scavenging of radioactive particulate matter from the atmopshere, J. Meteor., 14, 115-125, doi:10.1175/15200469(1957)014<0115:RSORPM>2.0.CO;2, 1957.

Hoose, C., Lohmann, U., Erdin, R., and Tegen, I.: The global influence of dust mineralogical composition on heterogeneous ice nucleation in mixed-phase clouds, Environ. Res. Lett., 3, 025003 , doi:10.1088/1748-9326/3/2/025003, 2008.

Ickes, L., Welti, A., Hoose, C., and Lohmann, U.: Classical nucleation theory of homogeneous freezing of water: thermodynamic and kinetic parameters, Phys. Chem. Chem. Phys., 17, 55145537, doi:10.1039/C4CP04184D, 2015.

Jung, C. H. and Lee, K. W.: Filtration of fine particles by multiple liquid droplet and gas bubble systems, Aerosol Sci. Tech., 29, 389-401, doi:10.1080/02786829808965578, 1998.

Laakso, L., Grönholm, T., Rannik, Ü., Kosmale, M., Fiedler, V., Vehkamäki, H., and Kulmala, M.: Ultrafine particle scavenging coefficients calculated from 6 years field measurements, Atmos. Environ., 37, 3605-3613, doi:10.1016/S1352-2310(03)00326-1, 2003.

Ladino, L.: Experiemntal study on collection efficiency and conatact freezing of aerosols in new collision chamber, $\mathrm{PhD}$ thesis, ETH, Zuerich, Switzerland, 2011.

Ladino, L., Stetzer, O., Hattendorf, B., Günther, D., Croft, B., and Lohmann, U.: Experimental Study of Collection Efficiencies between Submicron Aerosols and Cloud Droplets, J. Atmos. Sci., 68, 1853-1864, doi:10.1175/JAS-D-11-012.1, 2011a.

Ladino, L., Stetzer, O., Lüöend, F., Welti, A., and Lohmann, U.: Contact freezing experiments of kaolinite particles with cloud droplets, J. Geophys. Res, 116, D22202, doi:10.1029/2011JD015727, 2011 b.

Ladino Moreno, L. A., Stetzer, O., and Lohmann, U.: Contact freezing: a review of experimental studies, Atmos. Chem. Phys., 13, 9745-9769, doi:10.5194/acp-13-9745-2013, 2013.

Lai, K.-Y., Dayan, N., and Kerker, M.: Scavenging of Aerosol Particles by a Falling Water Drop, J. Atmos. Sci., 35, 674-682, doi:10.1175/1520-0469(1978)035<0674:SOAPBA>2.0.CO;2, 1978.

Leong, K. H., Beard, K. V., and Ochs, H. T.: Laboratory Measurements of Particle Capture by Evaporating Cloud Drops, J. Atmos. Sci., 39, 1130-1140, doi:10.1175/15200469(1982)039<1130:LMOPCB>2.0.CO;2, 1982.

Leong, K. H., Beard, K. V., and Stukel, J. J.: The Collision of Nonspherical Aerosol Particles with Small Evap- 
orating Water Drops, Aerosol Sci. Tech., 4, 445-454, doi:10.1080/02786828508959069, 1985.

Lohmann, U. and Diehl, K.: Sensitivity Studies of the Importance of Dust Ice Nuclei for the Indirect Aerosol Effect on Stratiform Mixed-Phase Clouds, J. Atmos. Sci., 63, 968-982, doi:10.1175/JAS3662.1, 2006.

Lohmann, U. and Hoose, C.: Sensitivity studies of different aerosol indirect effects in mixed-phase clouds, Atmos. Chem. Phys., 9, 8917-8934, doi:10.5194/acp-9-8917-2009, 2009.

Lüönd, F., Stetzer, O., Welti, A., and Lohmann, U.: Experimental study on the ice nucleation ability of size-selected kaolinite particles in the immersion mode, J. Geophys. Res.-Atmos., 115, D14201, doi:10.1029/2009JD012959, 2010.

Maria, S. F. and Russell, L. M.: Organic and Inorganic Aerosol Below-Cloud Scavenging by Suburban New Jersey Precipitation, Environ. Sci. Technol., 39, 4793-4800, doi:10.1021/es0491679, 2005.

Maring, H., Savoie, D. L., Izaguirre, M. A., Custals, L., and Reid, J. S.: Mineral dust aerosol size distribution change during atmospheric transport, J. Geophys. Res., 108, 8592, doi:10.1029/2002JD002536, 2003.

Nagare, B., Marcolli, C., Welti, A., Stetzer, O., and Lohmann, U.: Comparing contact and immersion freezing from continuous flow chambers, Atmos. Chem. Phys. Discuss., in preparation, 2015.

Nicolet, M., Stetzer, O., Lüönd, F., Möhler, O., and Lohmann, U.: Single ice crystal measurements during nucleation experiments with the depolarization detector IODE, Atmos. Chem. Phys., 10, 313-325, doi:10.5194/acp-10-313-2010, 2010.

Park, S., Jung, C., Jung, K., Lee, B., and Lee, K.: Wet scrubbing of polydisperse aerosols by freely falling droplets, J. Aerosol Sci., 36, 1444-1458, doi:10.1016/j.jaerosci.2005.03.012, 2005.

Prodi, F., Santachiara, G., Belosi, F., Vedernikov, A., and Balapanov, D.: Phoretic forces on aerosol particles surrounding an evaporating droplet in microgravity conditions, Atmos. Res., 142, 40-44, doi:10.1016/j.atmosres.2013.09.001, 2014.

Pruppacher, H. R. and Klett, J. D.: Microphysics of Clouds and Precipitation, Kluwer: Dordrecht, the Netherlands, 1997.

Radke, L. F., Hobbs, P. V., and Eltgroth, M. W.: Scavenging of Aerosol Particles by Precipitation, J. Appl. Meteorol., 19, 715-722, doi:10.1175/15200450(1980)019<0715:SOAPBP>2.0.CO;2, 1980.

Rogers, D. C.: Development of a continuous flow thermal gradient diffusion chamber for ice nucleation studies, Atmos. Res., 22, 149-181, doi:10.1016/0169-8095(88)90005-1, 1988.

Santachiara, G., Prodi, G., and Belosi, F.: A Review of Termo- and Diffusio-Phoresis in the Atmospheric Aerosol Scavenging Process. Part 1: Drop Scavenging, Atmospheric and Climate Sciences, 2, 148-158, doi:10.4236/acs.2012.22016, 2012.

Seinfeld, J. H. and Pandis, S. N.: Atmospheric Chemistry and Physics: From Air Pollution to Climate Change: John Wiley \& Sons, Inc., 2006.

Slinn, W. G. N.: Precipitation scavenging, in: Atmospheric Sciences and Power Production, Chap. 11, Division of Biomedical Environmental Research, US Department of Energy, Washington DC, USA, 1983.

Slinn, W. G. N. and Hales, J. M.: A Reevaluation of the Role of Thermophoresis as a Mechanism of In- and Below-Cloud
Scavenging, J. Atmos. Sci., 28, 1465-1471, doi:10.1175/15200469(1971)028<1465:AROTRO>2.0.CO;2, 1971.

Stetzer, O., Baschek, B., Lüönd, F., and Lohmann, U.: The Zurich Ice Nucleation Chamber (ZINC)-A New Instrument to Investigate Atmospheric Ice Formation, Aerosol Sci. Tech., 42, 64-74, doi:10.1080/02786820701787944, 2008.

Tegen, I. and Schepanski, K.: The global distribution of mineral dust, in: IOP Conf. Ser.: Earth Environ. Sci., Vol. 7, 012001, doi:10.1088/1755-1307/7/1/012001, 2009.

Tinsley, B. A.: Electric charge modulation of aerosol scavenging in clouds: Rate coefficients with Monte Carlo simulation of diffusion, J. Geophys. Res.-Atmops., 115, D23211, doi:10.1029/2010JD014580, 2010.

Tinsley, B. A. and Leddon, D. B.: Charge modulation of scavenging in clouds: Extension of Monte Carlo simulations and initial parameterization, J. Geophys. Res.-Atmos., 118, 8612-8624, doi:10.1002/jgrd.50618, 2013.

Tinsley, B. A., Rohrbaugh, R. P., Hei, M., and Beard, K. V.: Effects of Image Charges on the Scavenging of Aerosol Particles by Cloud Droplets and on Droplet Charging and Possible Ice Nucleation Processes, J. Atmos. Sci., 57, 2118-2134, doi:10.1175/1520-0469(2000)057<2118:EOICOT>2.0.CO;2, 2000.

Tinsley, B. A., Zhou, L., and Plemmons, A.: Changes in scavenging of particles by droplets due to weak electrification in clouds, Atmos. Res., 79, 266-295, doi:10.1016/j.atmosres.2005.06.004, 2006.

Ulmke, H., Wriedt, T., and Bauckhage, K.: Piezoelectric Droplet Generator for the Calibration of Particle-Sizing Instruments, Chem. Eng. Technol., 24, 265-268, doi:10.1002/15214125(200103)24:3<265::AID-CEAT265>3.0.CO;2-4, 2001.

Wang, P. K. and Pruppacher, H. R.: An Experimental Determination of the Efficiency with Which Aerosol Particles are Collected by Water Drops in Subsaturated Air, J. Atmos. Sci., 34, 1664-1669, doi:10.1175/1520-0469(1977)034<1664:AEDOTE>2.0.CO;2, 1977.

Wang, P. K., Grover, S. N., and Pruppacher, H. R.: On the Effect of Electric Charges on the Scavenging of Aerosol Particles by Clouds and Small Raindrops, J. Atmos. Sci., 35, 1735-1743, doi:10.1175/1520-0469(1978)035<1735:OTEOEC>2.0.CO;2, 1978.

Wang, X., Zhang, L., and Moran, M. D.: Uncertainty assessment of current size-resolved parameterizations for below-cloud particle scavenging by rain, Atmos. Chem. Phys., 10, 5685-5705, doi:10.5194/acp-10-5685-2010, 2010.

Young, K. C.: The Role of Contact Nucleation in Ice Phase Initiation in Clouds, J. Atmos. Sci., 31, 768-776, doi:10.1175/15200469(1974)031<0768:TROCNI>2.0.CO;2, 1974.

Yun, Y. and Penner, J. E.: Global model comparison of heterogeneous ice nucleation parameterizations in mixed phase clouds, J. Geophys. Res.-Atmos., 117, D07203, doi:10.1029/2011JD016506, 2012.

Zhou, L., Tinsley, B. A., and Plemmons, A.: Scavenging in weakly electrified saturated and subsaturated clouds, treating aerosol particles and droplets as conducting spheres, J. Geophys. Res.Atmos., 114, D18201, doi:10.1029/2008JD011527, 2009. 